\title{
العلامات الفارقة \\ ومدى الحاجة إليها في حوسبة اللغة
}

دـ .محمود محم خليل نصر الله

مدرس بالتربية والتعليم - مصر

تقديم :

وضع اللغويون لأقسام الكلم - مفردة ومركبة - علامات فارقة ، وبينوا

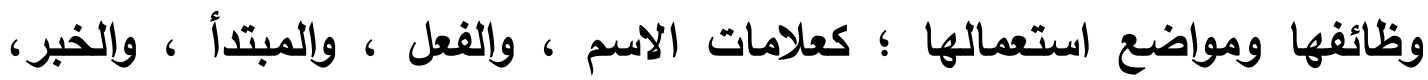
والفاعل ، والمفعول ، وغير ذلك ، واشتملت التعريفات الاصطلاحية على كثير من العلامات التي تكثف عن الفوارق اللفظية والمعنوية بين أنواع الكلم في تراكيبها المختلفة ، وتحدد وظائفها في سياقاتها المتعددة .

ومن خلال الممارسات التطبيقية ؛ بدا أن الوقوف أمام تلك العلامات والتعريفات لم يعد أمرًا ذا بالٍ لاعتباراتٍ ، من أهمها : عدم وجود علامات أو

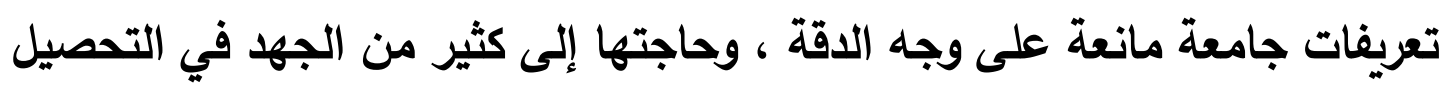
والاستظهار مع قلة الفائدة عند التطبيق معلى

وأمام التقدم العلمي والتقني المتنامي وظهور الحاسب الآلي ودخوله ميدان البحث اللغوي باعتباره وسيلة فاعلة ؛ فقد تبدلت الأمور ، وشعر الباحثون بحاجتهم الملحة إلى العودة من جديد إلى تلك العلامات ؛ لاختيار ما يرونه منها مناسبًا لعمليات الترميز عند المعالجة الآلية للنصوص ، والتفريق إلى بين التهاتئ المتثابهات وتجنب أسباب الخلط والإبهام بعد النجاح الكبير الذي شهدته الحوسبة اللغوية في عمليات التخزين والاسترجاع والترجمة الآلية وغير ذلك.

وقد لا تفي علامات النحاة بالمطلوب ، فيصبح الأمر في حاجة إلى ابتكار

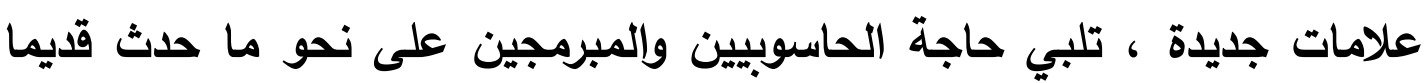

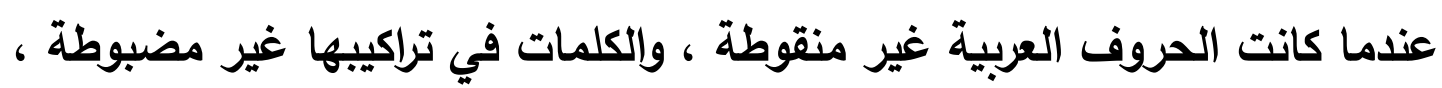


فانتشر اللحن ، وفشا الخلط ، واحتاج الأمر إلى التفريق بين المتشابهات ، وتحديد الوظائف اللغوية المختلفة للكلم ، فقام أبو الأسود الدؤلي بابتكار نقط الأل الإعراب ، ثم قام من بعده نصر بن عاصم ويحيى بن يعمر من تلاميذه بابتكار

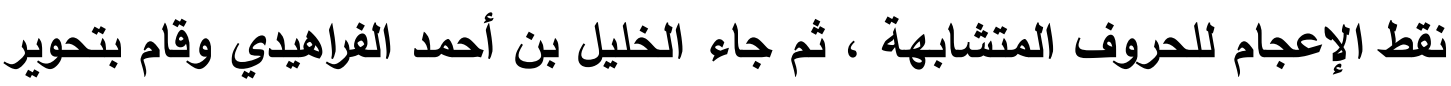
نقط الإعراب إلى علامات للضبط ، واستمرت المحاولات في التحوير والتطوير وابتكار العلامات ؛ حتى استقرت اللغة نقطا وضبطا ، وتميزت حروفها ووظائفها

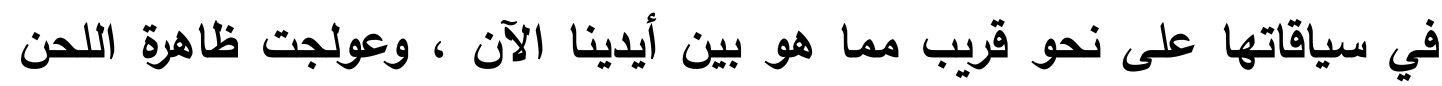

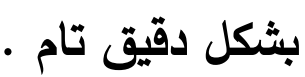

ومن هذا المنطلق ؛ نشأت فكرة هذا البحث ، وبدت الحاجة ملحة لتتبع

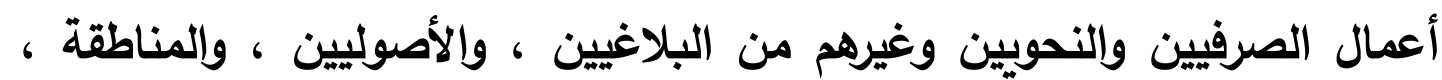

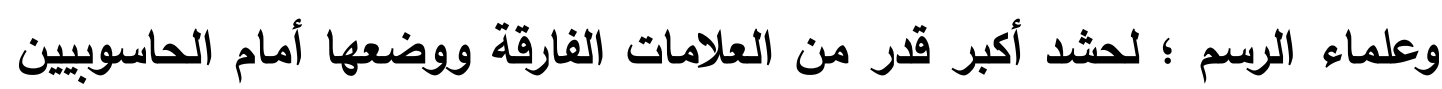
والمبرمجين لسد حاجة الترميز الآلي ، ووضع تصور نظري يتناسب مع المعالجات الآلية لعمليات إدراك النصوص ، تمهيدًا لتصميم برامج عملية يمكن عن طريقها التمييز بين أنواع الكلم ووظائفها المختلفة آليا .

وإذا كان الإطار النظري يمثل عند حوسبة اللغة ضرورة ملحة ؛ فإن نجاحه يظل مرتهناً بما تفرزه جهود العلماء والباحثين من قدرات تطبيقية ، ويعد تحديًا

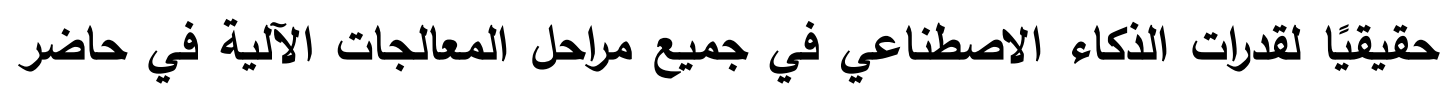

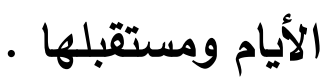

وأمام كثرة العلامات الفارقة فلن يستطيع هذا البحث بمفرده تحقيق تلك

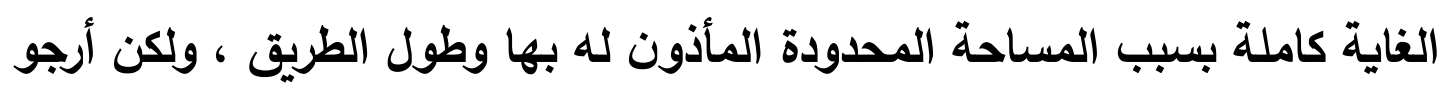
أن يكون أشبه بسابقة أعمال ، أو خطوة تتبعها - بإذن الله - خطوات ؛ حتى لهـ يصل المشروع إلى نهايته ، ويتحقق الهدف المزمع منه. 


\section{مراحل حوسبة اللغة وإثكالاتها:}

تتم عمليات الحوسبة الآلية للغة - كما هو معروف - من خلال ثلاث مراحل ، أو ثلاث خطوات أساسية ، تمثل كل واحدة منها عمليات لغوية وحاسوبية ضخمة ومعقدة ، وتحتاج إلى جهود مشتركة من اللغويين والحاسوبيين ، وتلك المراحل هي : n

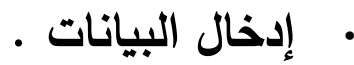

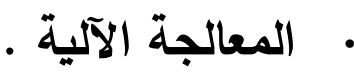

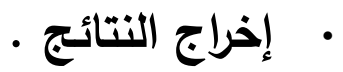

ويمكن توضيح ذلك بالثكل التالي :

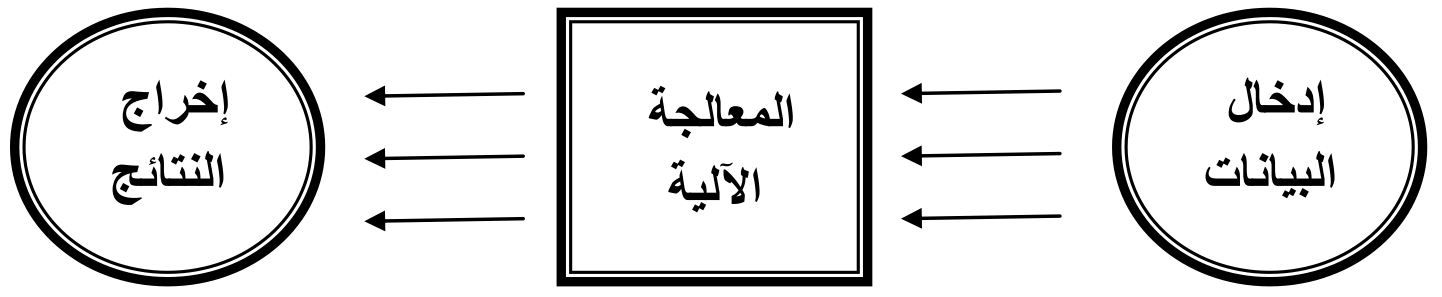

وليس من طبيعة هذا البحث أن يتناول بالتفصيل خصائص المرحلتين : الثانية والثالثة ، فيسعى لوضع برامج حاسوبية للمعالجة الآلية ، أو يبحث في

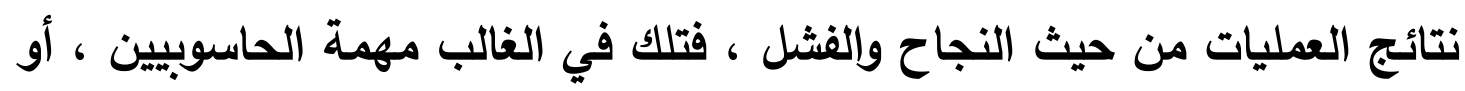
مهمة تالية لما ينشده ، فالهدف منه - كما هو معلن في عنوانه ومقدمته - هو بيان كيف يمكن حشد أكبر قدر من العلامات اللغوية الفارقة للاستعانة بها في الترميز الحاسوبي ، واختيار المناسب منها للتفريق بين مختلف العناصر ووظائفها

وتحديد أنماط التراكيب عند معالجتها آليًا.

ولعل تلك هي أهم الإثكاليات التي تواجه البرمجة على الإطلاق ؛ إذ كيف

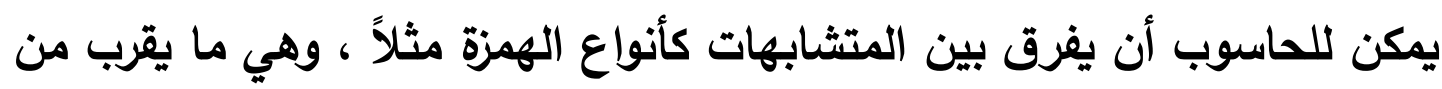
عشرين نوعاً كما أثشار إلى ذلك ابن خالويها ، وقد تنقسم بعض هذه الأنواع إلى ماتى 
أقسام أخرى ، فلهمزة الاستفهام وحدها ثلاثة عشر نوعًا ، ولكل نوع وظيفته الخاصة به امبام 1.

وما يقال عن الهمزة يقال في غيرها ، فلباء أحد عشر معنى ، كما ذكر أبو

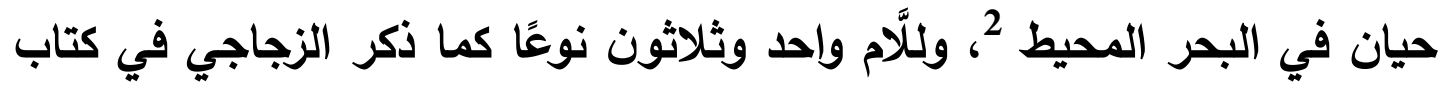

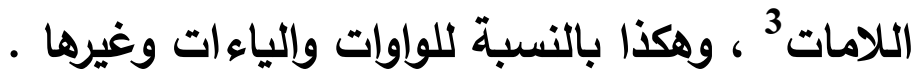

بل كيف يمكن التفريق بين المعاني المختلفة للمشترك اللفظي ؛ كما في حالة الفعل " ضرب " مثثلاً في السياقات اللغوية المختلفة من مثل : • ضرب عحم أخاه : فعل به الضرب وعاقبه وأدبه . . • وضرب القاضي على يايه : حجر عليه ومنعه من التصرف . • وضرب في الأرض : أبعد فيها وسعى للرزق والتجارة . • وضرب في سبيل الله : قاتل وجاهد . • وضرب مثلًا : أعطى مثثلاً . • وضرب في الأمر بسهم : شارك فيه . • وضرب أخماسًا في أسداس : تحير. • وضرب به عُؤض الحائط : أهمله وتركه احتقارًا لشأنه . • وضرب العملة : سكها . • وضرب العلي : صاغها . • وضرب عددًا في آخر : كرره بعدد مرات الآخر •

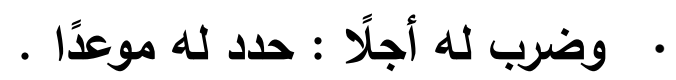
• وضرب عليه الحصار : حاطه وضيق عليه . • وضرب عليهم الذلة : أذاقهم بأسها .

• وضرب الشيء بالشيء : خلطه .

1. كتاب الألفات لابن خالويه : 20 - 69 ، والمعجم الكبير ، حرف الهمزة : 1 / 4 ـ .

2.

3. كتاب اللامات للزجاجي : 31 ، 32 ، 32 . 


$$
\begin{aligned}
& \text { • مضرب الأرز : قشره . } \\
& \text { • وضرب عليهم الخراج : ألزمهم به . . } \\
& \text { · وضرب الرقم القياسي : تعدى إلى رقم لم يبلغه أحد . ل . } \\
& \text { • وضرب الوتِد : دقه في الأرض . } \\
& \text { • وضربته العقرب : لاغته . } \\
& \text { · وضربته الحمى ونحوها : أصابته : . }
\end{aligned}
$$

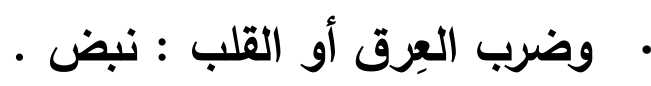

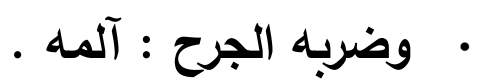

$$
\begin{aligned}
& \text { • وضربها الموج : تحرك واصطدم به : . }
\end{aligned}
$$

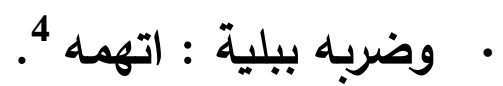

وكما سبقت الإشارة آنفًا ؛ فقد حدث ذلك قديمًا عندما كانت الصروف العربية غير منقوطة ، والكلمات في تراكيبها غير مضبوطة ، فانتشر اللحن ، واحتاج

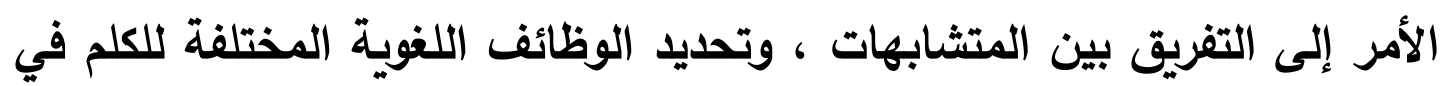
مواضعه بكل دقة .

ولقد كان أبو الأسود الاؤلي موفقًا غاية التوفيق حينما جعل من النقط

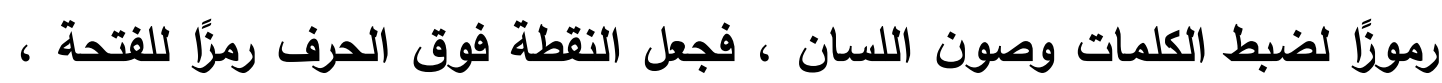

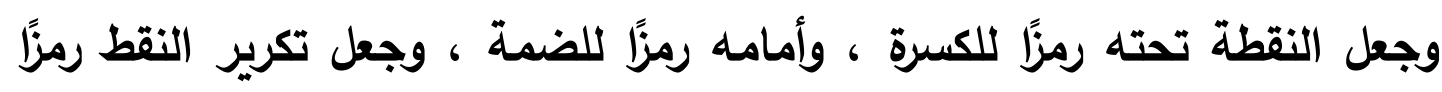

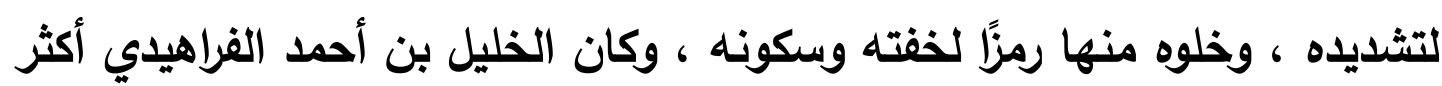

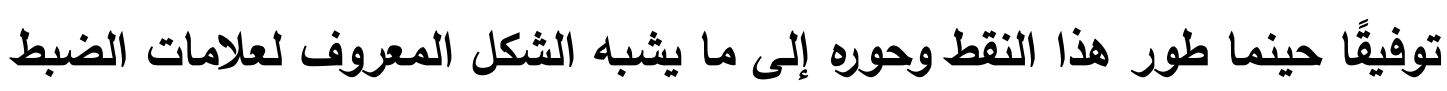
الآن ، فجعل الألف المنبطحة فوق الحرف علامة أو رمزًا لفتحه ، وجعل الألف وحتف المنبطحة تحته علامة لكسره ، وجعل الواو الصغيرة علامة للضم ، ورأس الخاء

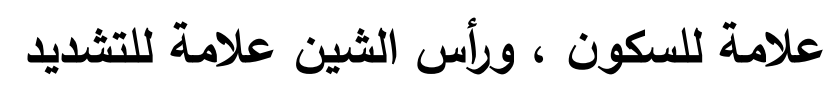

4. لسان العرب لابن منظور ، مادة : ضرب : 2 / 31 ، ، والمعجم الوجيز ، مجمع اللغة العربية ، مادة : ضرب ، 378 . 
وبجانب نقط أبي الأسود ؛ وضع نصر بن عاصم ويحيى بن يعمر نقطًا آخر بلون مختلف للتمييز بين الحروف المتثابهة ، فميزوا بين الباء والتاء وإلثاء والنون والياء بنقطا في مواضع مختلفة ، وميزوا بين الجيم والحاء والخاء ، وبين الدال والذال ، وهكذا فعلوا في جميع الحروف المتثابهة ، فأضافوا رموزًا أخرى

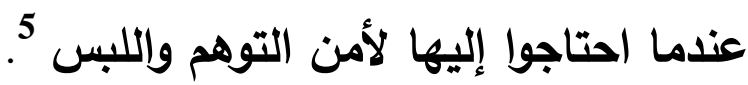

وكان ابن مالك موفقًا ومنطقيًا أيضًا حينما بدأ ألفيته بتحديد العلامات الفارقة بين العناصر اللغوية المختلفة ، فبدأ بالتفريق بين الكلام والكلم والكلمة

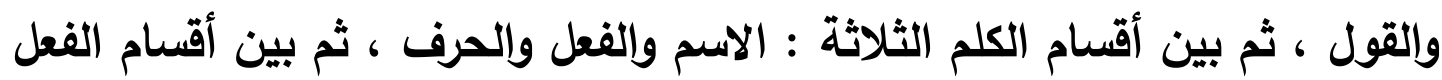

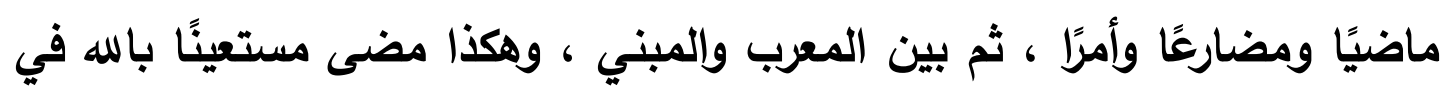
ألفيته ، يفرق بين الأصول والفروع في جميع الأقسام والأنواع .

وكان يقف أحيانًا أمام المتشابهات ليحثد العلامات التي تفرق بينها من

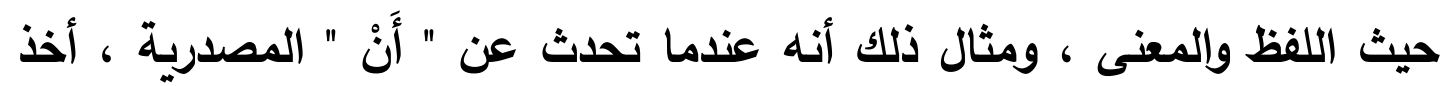

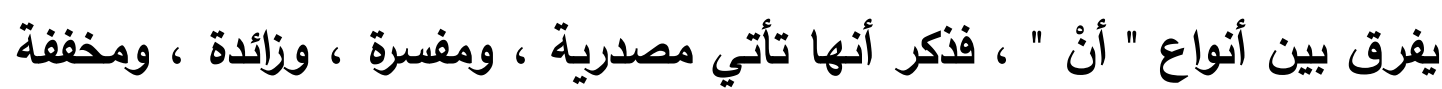

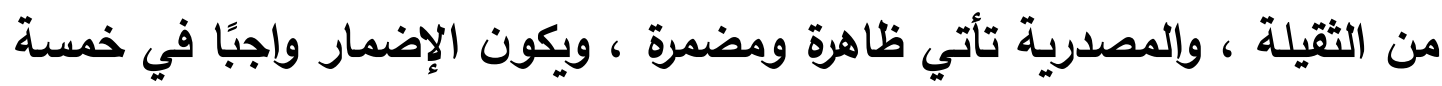

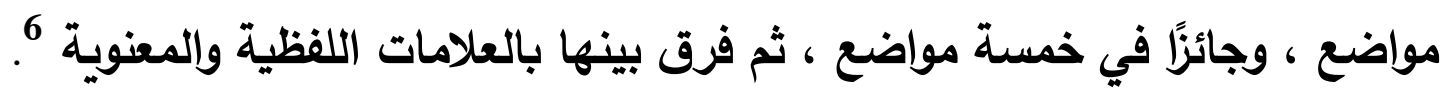

وقريبًا من ذلك ما فعله علماء اللغة المحدثون عندما رأوا أن الأبجديات العالمية قاصرة عن تمثيل الأصوات المنطوقة بكل دقة ، فقد يمثل الصوت الواحد

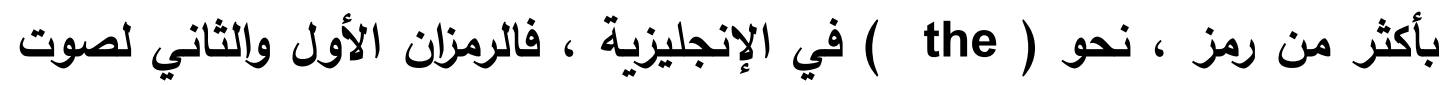

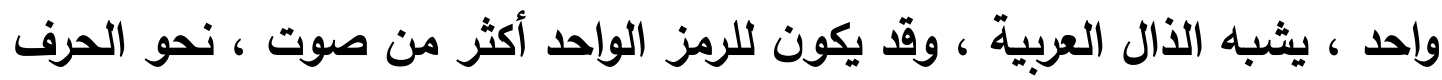

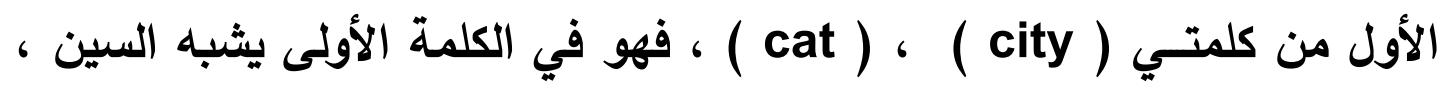

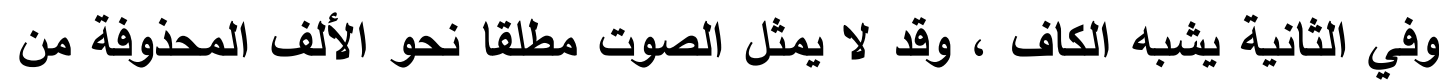


اسم الإشارة ( هذا ) والواو المحذوفة من ( داود )، وقد يؤتى برمز ولا صوت لله ، نحو الألف الأخيرة من ( قالوا ) والواو من ( عمرو وأولئك ) .

ومن أجل ذلك بدأت المحاولات منذ القرن السادس عثر الميلادي لوضع

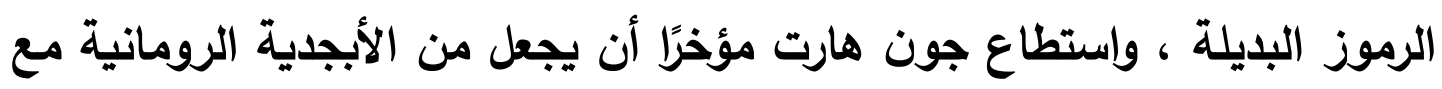

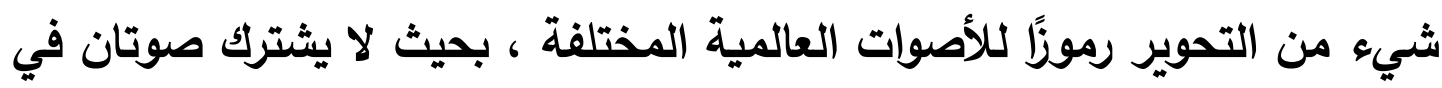

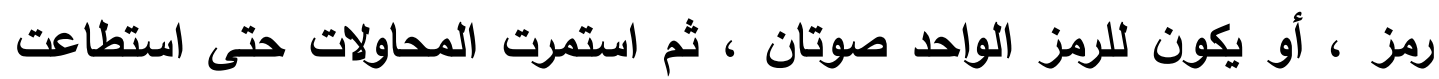
الجمعية الصوتية الدولية التي تأسست عام 1886 م أن تضع الأبجدية التونية الدولية

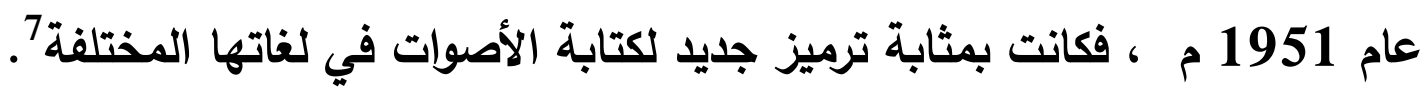
وعندما ظهرت الآلة الكاتبة اصطدمت باللغة ، وبذلت محاولات كثيرة لتقديم البدائل المختلفة لكتابة الحروف العربية على وجه التحديد ، وانتهت تلك المحاولات بضرورة تطويع الآلة للغة وليس العكس 8 .

وفي الآونة الأخيرة ؛ دخل الحاسوب ميدان اللغة ، ولم يقتصر استخدامه

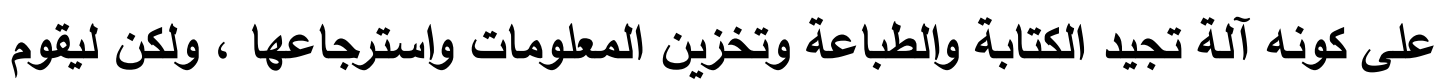
بعليات التحليل الصوتي والصرفي والنحوي والدلالي آليًا ، واقتضى ذلك إعادة النظر في اللغة للبحث عن علامات ورموز تعين على إعداد البرامج اللازمة لإجراء العمليات الحاسوبية آليًا ، وعقد من أجل ذلك الكثير من المؤتمرات والندوات لاستيعاب المزيد من التقنيات وإبراز العلاقات التبادلية بين اللغات 9.

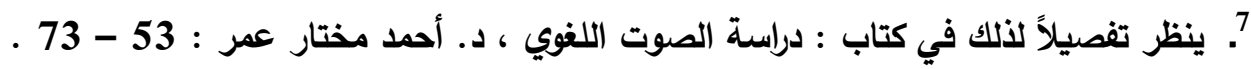

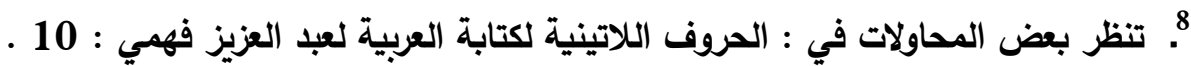

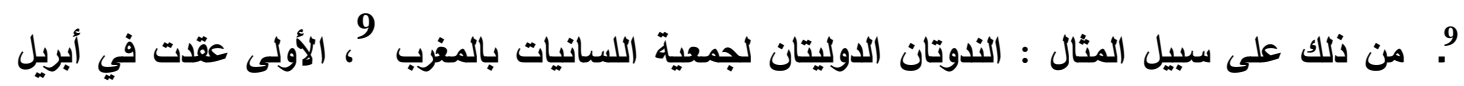

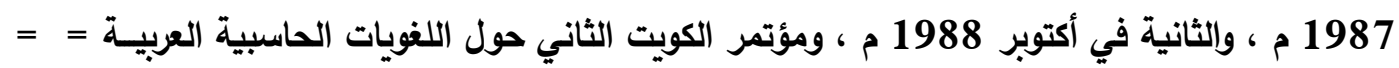

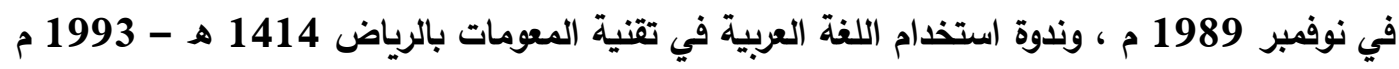
، وندوة اللغة العربية والثقافة العلمية ، القاهرة ، 1996 م، والمؤتمر الثاني لتعريب العلوم ، القاهرة 


\section{أنواع العلامات الفارقة :}

باستقراء جهود النحويين القدماء والمحدثين ، تبين لي أن العلامات الفارقة في العربية ترجع إلى أمرين ، هما :

المعاني الإفرادية وهي ما يكون للكلم قبل التركيب ، وتتمثل في نوعين :

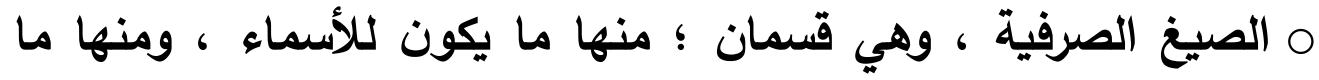
يكون للأفعال ، وقد تبدو بعض الصيغ مشتركة نحو فَعَل بفتح الأول

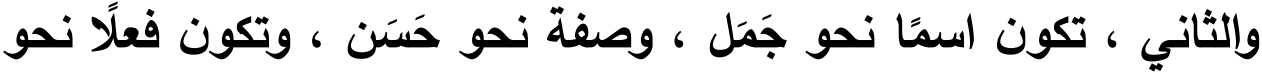

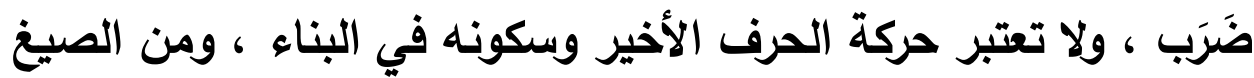

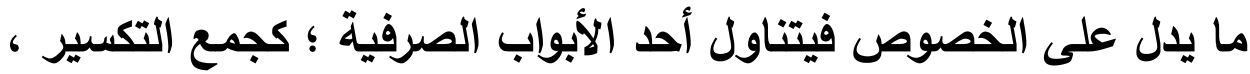

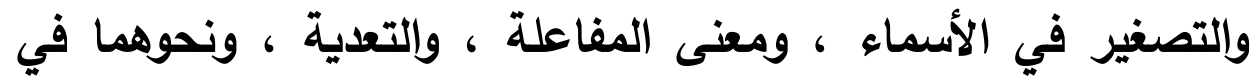
الأفعال 10.

م والوحدات الإلصاقية التي تدل على المعاني المختلفة ، سواءً أكانت سوابق أم دواخل ولواحق ؛ كالضمائر المتصلة للتكلم والخطاب والغيبة ،

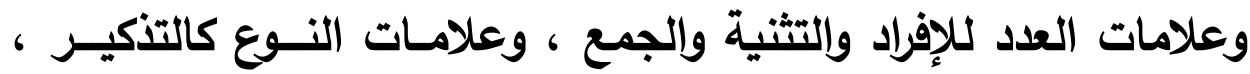

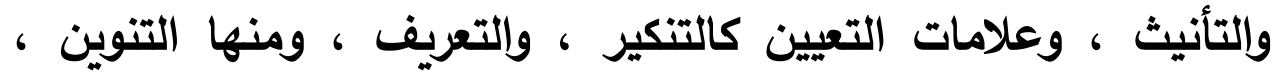
والنسب ، وأحرف المضارعة ، ونونا التوكيد ، ونون الوقاية 11 .

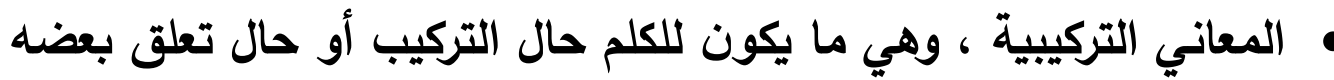
بعض ، وتتمثل في نوعين أيضًا ، هما :

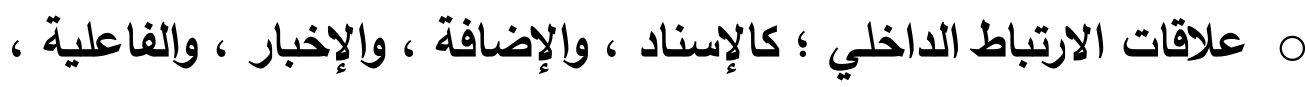
والمفعولية ، والتمييز ، والحالية ، والتبعية ، والتعليق ، ونحوها .

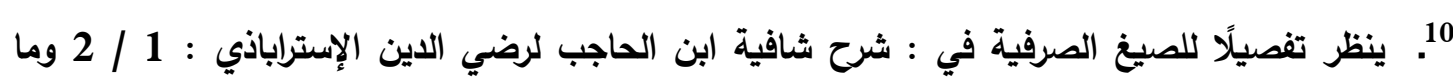

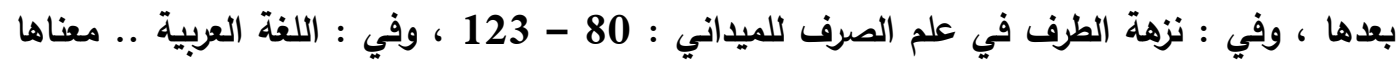

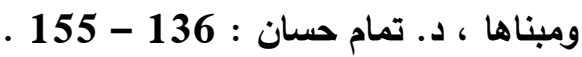

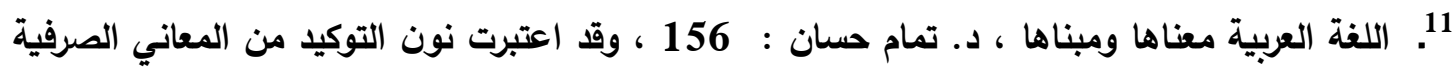

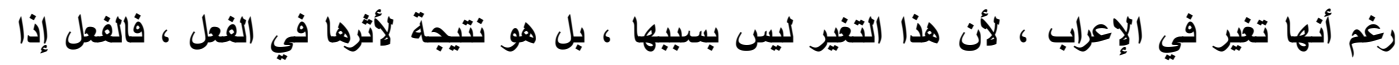

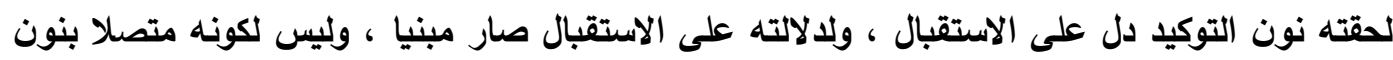
التوكيد سببا مباشرا في بنائه . 
م وأدوات الربط التي تدل على الفصل والوصل ؛ كحروف العطف ، والجر،

والتداء ، والتوكيد ، والاستقبال ، والتمني ، والنواصب ، والجوازم 12

$$
\text { أولاً : الصيخ الصرفية : }
$$

تمتاز العربية بمرونتها الصرفية بما تمتلك من صيغ كثيرة تميز أنواع الكلم المختلفة ،

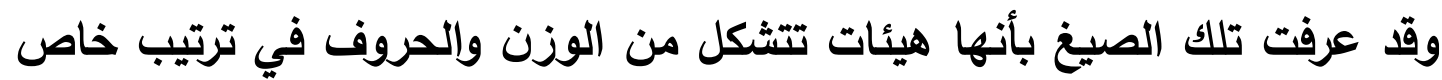

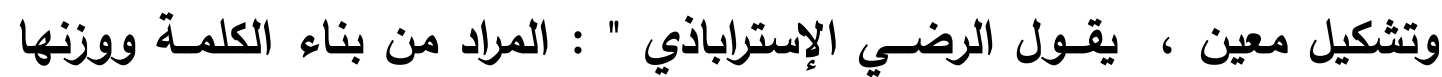

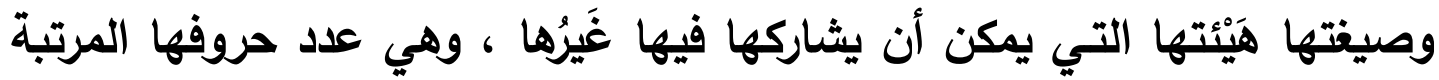
وحركاتها المعينة وسكونها ، مع اعتبار الحـروف الزائدة والأصلية كُلٌّ في موضعه 13.

وقد عقد لها النحاة فصولاً خاصة في كتبهم ، وقسموها إلى ثلاثية ورباعية وخماسية ، مجردة ومزيدة ، مضعفة وغير مضعفة ، وتعتبر تلك الصيغ جميعها علامات فارقة يمكن أن يوضع لكل منها رمز حاسوبي خاص للتعرف عليها 14.

ولهها عند المحدثين مسميات مختلفة ؛ منها أنها هي القالب الذي تصـاغ الكلمات على قياسه ، أو هي المثال أو النموذج الثكلي للكلمات ، أو هي النمط هـ الصرفي المنظم للأسـماء والأفعال الذي تثـتق مـن أصولها ، أو هي الهيئة التي ركبت فيها حروف الكلمة الأصلية والزائدة ، أو البناء الذي جمعت فيه لهنه ، وهو الذي الذي يعطي الكلمة صورتها وشكلها ، ويجعل لها جرسًا ووزنًا معينًا ، وغالبًا ما تستعمل

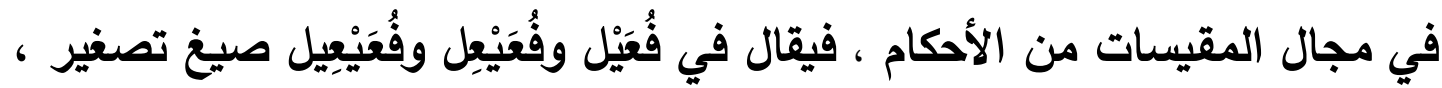
وفي فاعل من فعل صيغة اسم الفاعل ، وفي مفعول صيغة اسم المفعول 15 . 12. نظام الارتباط والربط في تركيب الجملة العربية ، د. مصطفى حميدة : 163 وما بعدها .

$$
\text { 13 } 13
$$

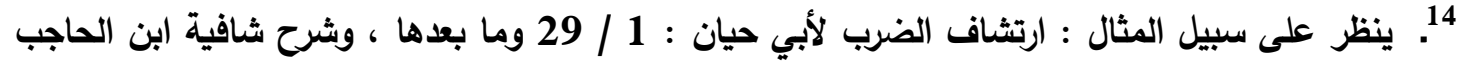

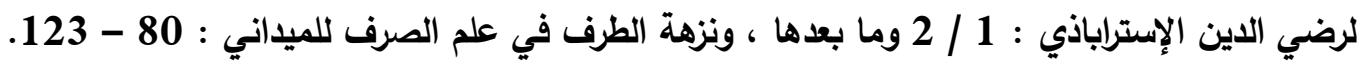

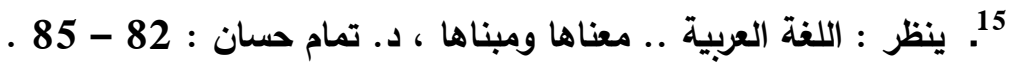


ومما سبق يتضح أن مصطلح الصيغة الصرفية له مفاهيم أخرى ترادفه ؛

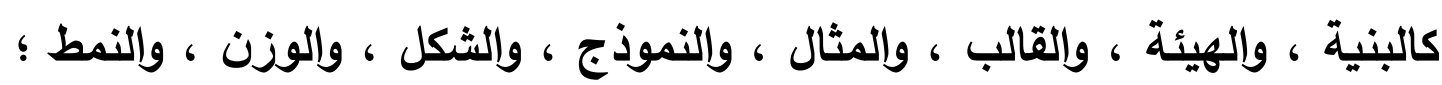

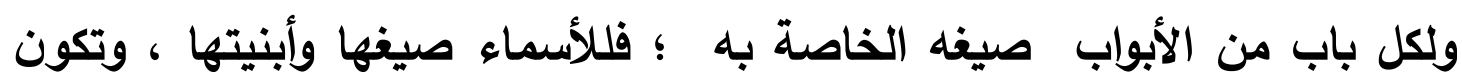
ثلاثية ورباعية وخماسية ، ويضاف إليها المصادر والمشتقات الوصفية ؛ وهي :

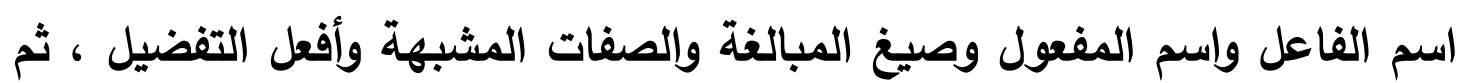
أسماء الزمان والمكان والآلة ، وغير ذلك 16 .

وقد تخرج بعض الأسماء عن باب الصيغة كالأسماء الأعجمية وأسماء

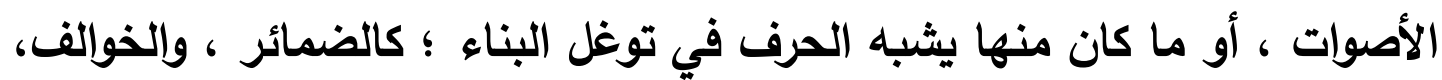

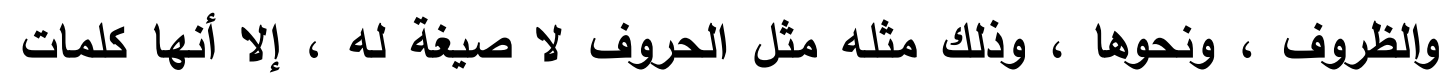
محدودة يمكن حصرها وتخزينها واسترجاعها بسهولة ويسر •

وللأفعال أبوابها وصيغها الخاصة ثلاثية أو رباعية ، فللثلاثي المجرد ستة أبواب ، هي : n (2)

ف فَعَل 4. 6.
1 1

3

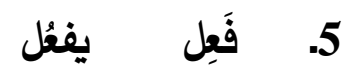

$$
\text { وللرباعي المجرد سبع صيغ ، هي : }
$$

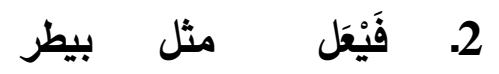

1 1

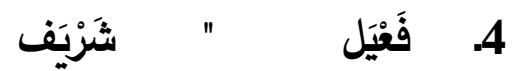

3

6.

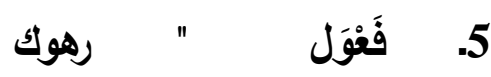

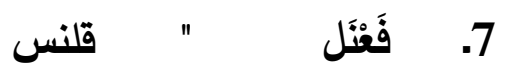

16. ينظر في أبنية الأسماء الأصلية والمتفرعة عنها : شرح شافية ابن الحاجب للرضي : 1 / 7 - 75 - 57 ،

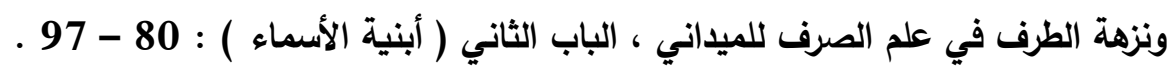




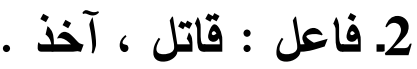

ويزاد الثلاثي ، وزيادته على ثلاثة أقسام : أ ـ ما زيل بحرف واحد :

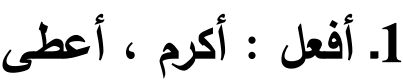

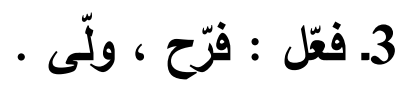

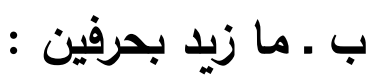

2. افتعل : اجتمع ، اشتق . 4. تفعّل : تعلّم ، تزكّى .

2. افعوعل : اغدودن ، اعشوشب .

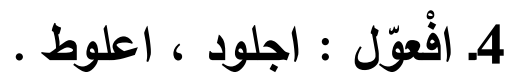

2. افعلّ : اقشعزّ ، اطمأنّ

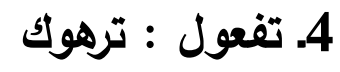
6. تفوْعل : تجورب 8. تفعلى : تسلقى .

2. افعنلى : اسلنقى 17
1. انفعل : انكسر ، انثق . 3. افعلّ : احمزّ ، اعوزّ . 5. تفاعل : تباعد ، تثاور . ج . ما زيا بثلاثة أحرف : 1. استفعل : استخرج ، استقام . 3. افْعالّ : احمار ، اشهاب.

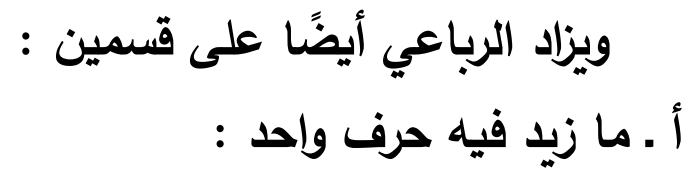
1. افعنلل : احرنجم 3. تفعلل : تجلبب 5. تفْيُعل : تشيطن : تهن 7. تمفْعل : تمسكن : تلتيطن ب ـ ما زيد فيه حرفان : 1. افعنلل : اقعنسس

وفي جميع الأحوال ؛ فإن أحرف الزيادة أو ما يسميه المحثثون بالوحدات الدلالية أو المورفيمات الاشتقاقية تؤدي دورًا مهمًا فيما يطرأ على الفعل المجرد من إضافات ، وبذلك تصبح الصيغة علامة تعمل على تحديد نوع الكلمة المفردة

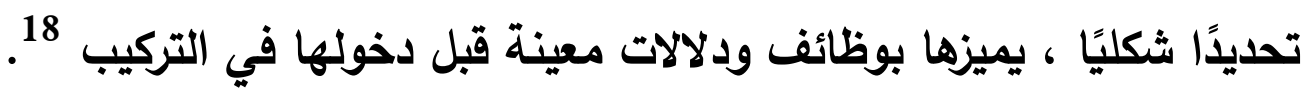
17.

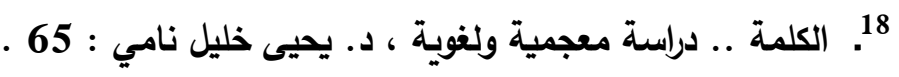


وفي كثير من الأحيان لا تكفي الصيغة بمفردها لتكون علامة فارقة ، تفصل بين أنواع الكلم لتثابه الصيغ في الثكل مع اختلاف المعنى ، مثل :

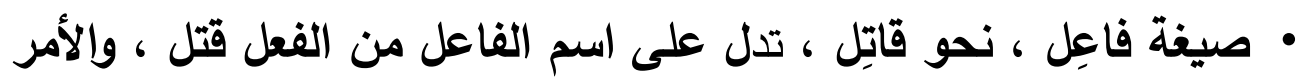
من قاتَل 19.

• صيغة فَعْل : صالحة للاسم المعين كبيت ، وللمصدر كضرب ، وللصفة كشهم

• صيغة تفَعل : للمضارع المسند إلى المخاطب والغائبة ، نحو : أنت تسمع ، وهي تسمع ، وأنت تضرب ، وهي تضرب .

وفي مثل هذه الحالات التي تختلط فيها الصيغ بعضها ببعض لا نجد إلا السياق باعتباره هو الذي يكثف عن القرائن اللفظية والمعنوية التي تفرق بين المتشابهات ، وعندئذ يتحتم اللجوء إلى جميع القرائن الممكنة والبحث عن علامات فارقة غير الصيغة للفصل بين المتشابهات ، وحتى الآن هناك صعوبات بالغة في إمكانية التمييز حاسوبيًا أو آليًا بين المعاني المختلفة للصيغ المتثابهة في

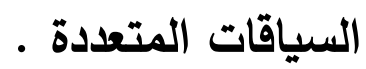

وبجانب ذلك ؛ فإن هناك كثيرًا من الألفاظ التي تخضع للقواعد التي تحكم تأليف الأصوات وتجاورها ؛ كالإعلال ، والإبدال ، والنقل ، والحذف ، وهذه تحتاج

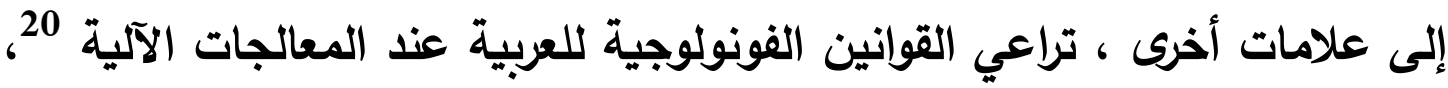
ومثل ذلك المعاني الوظيفية التي تميز الوحدات الدلالية الاشتقاقية ، وتمثل جزيًا من المعنى العام للصيغة ؛ كمعاني المشتقات ، ومعاني الصيغ الزوائد في الأفعال

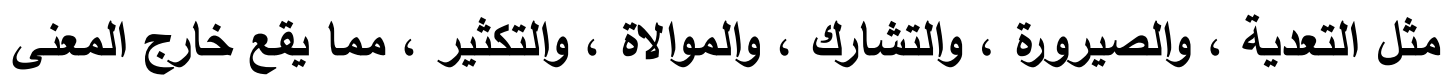
المعجي الذي يكشف عنه في القاموس والمعنى الدلالي الذي يفهم من السياق ،

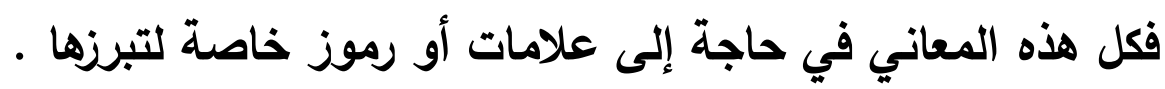

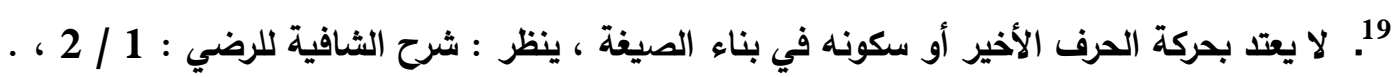

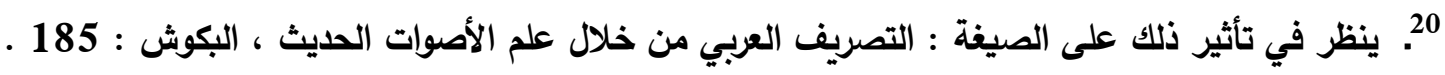


ومثله أيضًا الالالة على الزمن ، فالمعروف أن شكل الصيغة هو الذي يفرق بين الأفعال من حيث الزمن ، فصيفة " فعل " مثثلا مقصورة على الماضي ،

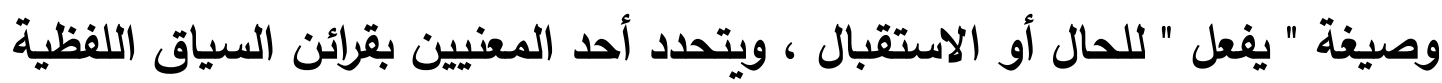
والمعنوية والحالية ، مما يعين على فهم الزمن في مجال أوسع من مجرد المجال الصرفي المحدود ، وذلك يحتاج إلى علامات فارقة إضافية 21 .

ولذلك ؛ فإنه يجب أن نستفيد من النظريات اللغوية التي يمكن أن تقدم حلاً في هذا المجال ؛ كنظرية الحقول الدلالية ، وما تتيحه من تطبيقات تقوم في بنائها على شبكة من المعاني الصرفية والنحوية المتداخلة ؛ كنوع الكلمة من حيث كونها

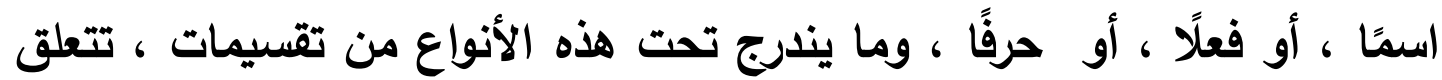

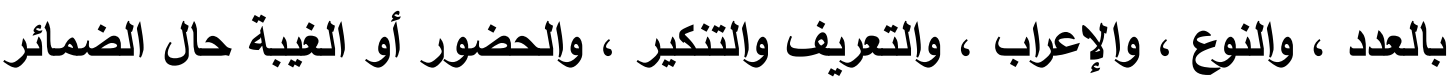
، ومن ثم اختيار العلامات والرموز المميزة التي تدل على ذلك ، واقتراح العلامات اللازمة لما ليس لله علامة مميزة أسوة بما حدث عند حاجة اللفة إلى شيء شبيه بهذا عبر عصورها المختلفة 22

ثانيًا : الوحدات الصرفية الإلصاقية : وهي التي تعطي اللفظ مع الصيغ الأساسية صورته النهائية ، وتحدد هيئة

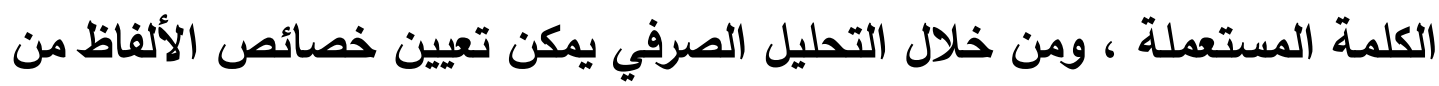

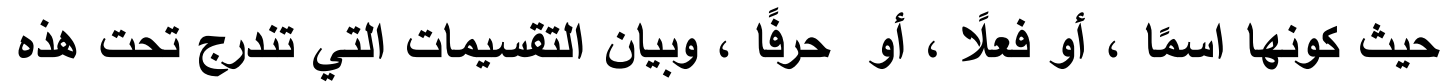

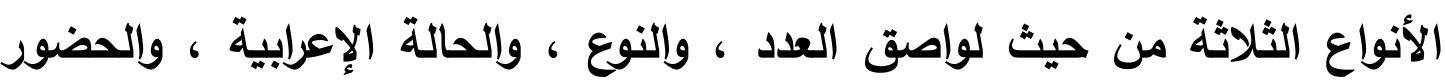
والغيبة ، والتعريف والتنكير ، والكشف عن تركيبها الداخلي من حيث الجذور ،

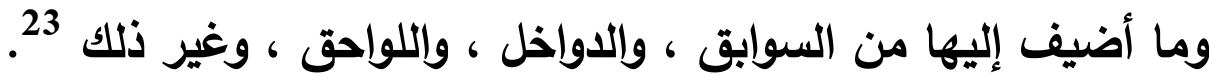

11. . ينظر في ذلك : اللغة بين المعيارية والوصفية ، د. تمام حسان : 119 ، واللغة العربية .. معناها

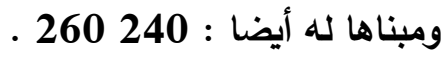
222.2

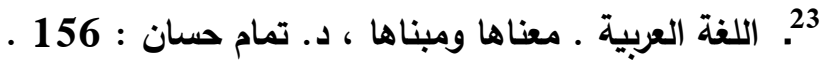


وقد أورد السيوطي في الأثباه والنظائر أنه من خلال تتبع ما ذكره سابقوه

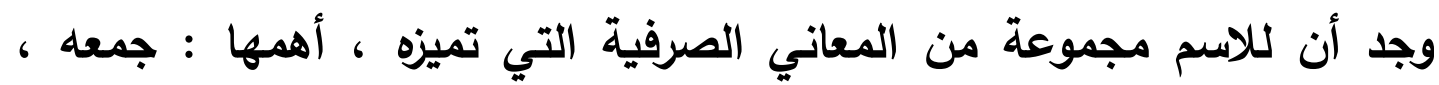

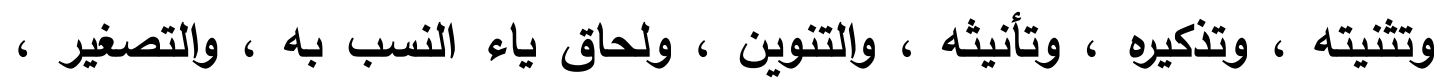

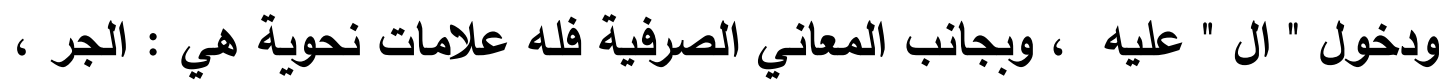
والنداء ، والإسناد إليه أو التحدث عنه ، كما أن للفعل كثيرًا من العلامات والمعاني

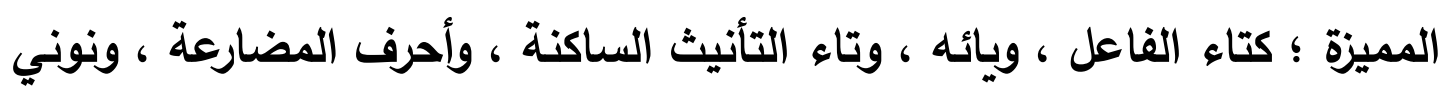

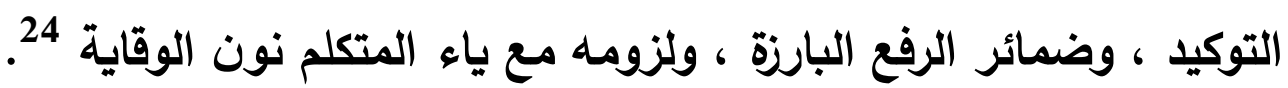

وإلى بعض ذلك أشار ابن مالك في ألفيته المشهورة بقوله :

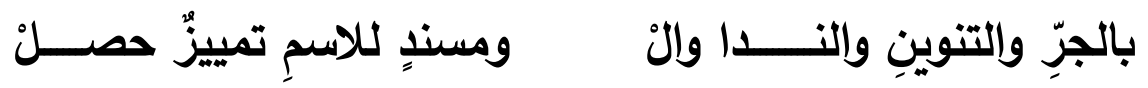

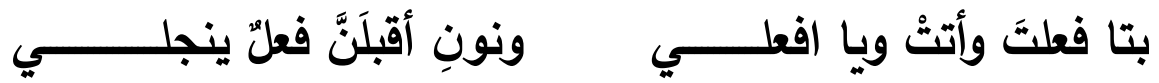

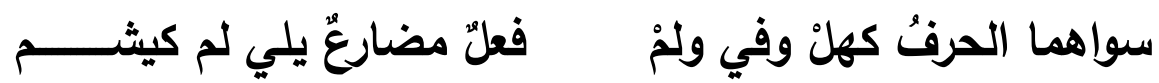

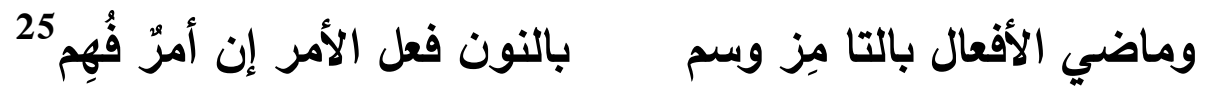

ويمكن لهذه العلامات اللغوية التي تدل على هذه المعاني أن تكون علامات

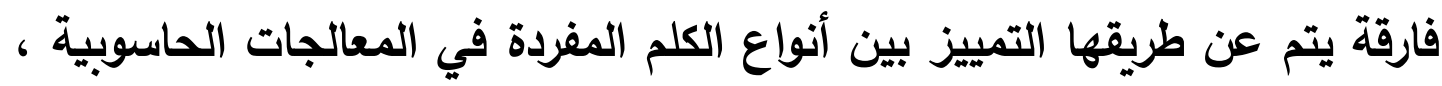
ومن خلال دمجها عن طريق عمليات التخزين والاسترجاع يتم استخدامها في برامج تحليل النصوص العربية ، عندما تكون الكلمة في صورتها النحوية ؛ أي

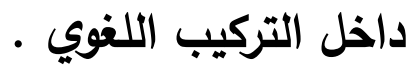

وعلى سبيل المثال ؛ إذا أخذنا ضمائر الرفع المتصلة التي تلحق الفعل فتدل على الفاعل مثلاً نجد أنها هي نفسها التي تدل على النوع أو الثخص أولى أو العدد ،

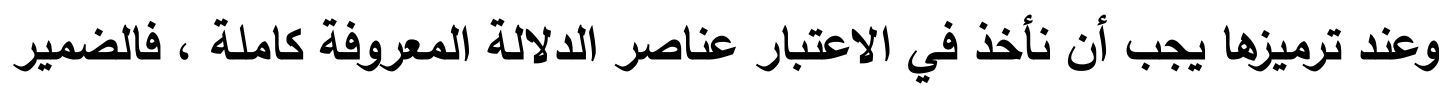

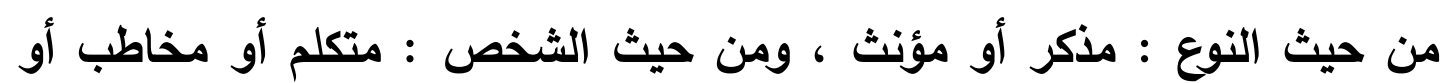


غائب ، ومن حيث العدد : مفرد أو مثنى أو جمع ، ويمكن توضيح ذلك كمثال

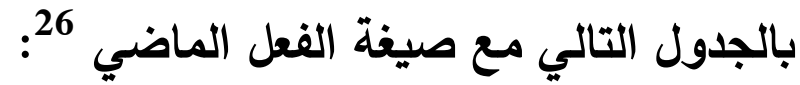

\begin{tabular}{|c|c|c|c|c|c|c|c|c|}
\hline \multicolumn{3}{|c|}{ العدد } & \multicolumn{3}{|c|}{ الشخص } & \multicolumn{2}{|c|}{ النوع } & \multirow{2}{*}{ الفعل } \\
\hline جمع & مثنى & مفرد & غائب & مخاطب & متكلم & مؤنث & مذكر & \\
\hline$x$ & $x$ & $\sqrt{ }$ & $x$ & $x$ & تُ & $\sqrt{ }$ & $\sqrt{ }$ & ضربتُ \\
\hline ناد & $x$ & $x$ & $x$ & $x$ & ناي & $\sqrt{ }$ & $\sqrt{ }$ & ضربنا \\
\hline$x$ & $x$ & $\sqrt{ }$ & $x$ & $\bar{F}$ & $x$ & $x$ & $\sqrt{ }$ & ضربتَ \\
\hline$x$ & $x$ & $\sqrt{ }$ & $x$ & تِ & $x$ & $\sqrt{ }$ & $x$ & ضربتِ \\
\hline$x$ & ما & $x$ & $x$ & تُ & $x$ & $\sqrt{ }$ & $\sqrt{ }$ & ضربتما \\
\hline p & $x$ & $x$ & $x$ & تُ & $x$ & $x$ & $\sqrt{ }$ & ضربتم \\
\hline ن் & $x$ & $x$ & $x$ & تُ & $x$ & $\sqrt{ }$ & $x$ & ضربتن \\
\hline$x$ & $x$ & $\sqrt{ }$ & $\sqrt{ }$ & $x$ & $x$ & $x$ & $\sqrt{ }$ & ضرب \\
\hline$x$ & $x$ & $\sqrt{ }$ & $\sqrt{ }$ & $x$ & $x$ & تُ & $x$ & ضربتت \\
\hline$x$ & $L$ & $x$ & $\sqrt{ }$ & $x$ & $x$ & $x$ & $\sqrt{ }$ & ضربا \\
\hline$x$ & $L$ & $x$ & $\sqrt{ }$ & $x$ & $x$ & 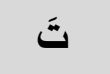 & $x$ & ضربتا \\
\hline 9 & $x$ & $\times$ & $\sqrt{ }$ & $x$ & $x$ & $x$ & $\sqrt{ }$ & ضربوا \\
\hline ن & $x$ & $x$ & $\sqrt{ }$ & $x$ & $x$ & $\sqrt{ }$ & $x$ & ضربن \\
\hline
\end{tabular}

ويلاحظ في هذا الجدول :

• أن المذكر ، والغائب ، والمفرد ليست لهم علامات دالة عليهم ، فيمكن اعتبارهم أصلاً ، يرمز له برمز معين ، ويبنى عليه غيره. • انتظام علامة المخاطب " ت "في جميع الحالات ، ويفرق بينها بالحركة. • اضطراب المؤنث ، فهو في حالة المتكلم والمثنى المخاطب متحد مع المذكر في علامته ، ومع الغائبة المفردة والمثنى تاء ، ولا توجد لله علامة مع المخاطبة والمخاطبات والغائبات.

6.26 تدل العلامة (ل) على اكتساب الفعل دلالة العنصر الموضحة أفقيا ، وتدل العلامة (×) على افتقاد الفعل لالالة العنصر ، وتدجل العلامة (¥) على ترجيح اكتساب الالالة دون أن تكون قاطعة في الاختصاص . 
• اضطراب الأمر أيضا بالنسبة لـ " نا " الفاعلين.

• لا يوجد في جميع الأفعال الماضية علامة تلال على النوع ، باستثناء

علامة الغائبة المفردة والمثناة.

ويختف الأمر قليلاً في المضارع ، والجدول التالي يوضح ذلك :

\begin{tabular}{|c|c|c|c|c|c|c|c|c|c|}
\hline \multicolumn{3}{|c|}{ العدد } & \multicolumn{3}{|c|}{ الشخص } & \multicolumn{2}{|c|}{ النوع } & \multirow{2}{*}{ المضارعة } & \multirow{2}{*}{ الفعل } \\
\hline جمع & مثنى & مفرد & غائب & مخاطب & متكلم & مؤنت & مذكر & & \\
\hline \multirow[t]{2}{*}{$x$} & $x$ & $\sqrt{ }$ & $x$ & $x$ & & $\sqrt{ }$ & $\sqrt{ }$ & أ & أضرب \\
\hline & $x$ & $x$ & $x$ & $x$ & & $\sqrt{ }$ & $\sqrt{ }$ & $\dot{ن}$ & نضرب \\
\hline$x$ & $x$ & $\sqrt{ }$ & $x$ & $\sqrt{ }$ & $x$ & $x$ & $\sqrt{ }$ & ت & تضرب \\
\hline$x$ & $x$ & $\sqrt{ }$ & $x$ & $\sqrt{ }$ & $x$ & ي & $x$ & ت & تضربين \\
\hline$x$ & 1 & $x$ & $x$ & $\sqrt{ }$ & $x$ & $\sqrt{ }$ & $\sqrt{ }$ & ت & تضربان \\
\hline 9 & $x$ & $x$ & $x$ & $\sqrt{ }$ & $x$ & $x$ & $\sqrt{ }$ & ت & تضربون \\
\hline نَ & $x$ & $x$ & $x$ & $\sqrt{ }$ & $x$ & $\sqrt{ }$ & $x$ & ت & تضربن \\
\hline$x$ & $x$ & $\sqrt{ }$ & $\sqrt{ }$ & $x$ & $x$ & $x$ & $\sqrt{ }$ & ي & يضرب \\
\hline$x$ & $x$ & $\sqrt{ }$ & $\sqrt{ }$ & $x$ & $x$ & $\sqrt{ }$ & $x$ & ت & تضرب \\
\hline$x$ & $L$ & $x$ & $\sqrt{ }$ & $x$ & $x$ & $x$ & $\sqrt{ }$ & ي & يضربان \\
\hline$x$ & $L$ & $x$ & $\sqrt{ }$ & $x$ & $x$ & $\sqrt{ }$ & $x$ & ت & تضربان \\
\hline 9 & $x$ & $x$ & $\sqrt{ }$ & $x$ & $x$ & $x$ & $\sqrt{ }$ & ي & يضربون \\
\hline$\dot{ن}$ & $x$ & $x$ & $\sqrt{ }$ & $x$ & $x$ & $\sqrt{ }$ & $x$ & ي & يضربن \\
\hline
\end{tabular}

ويلاحظ على هذا الجدول حذف ضمائر التكلم والخطاب اكتفاء ملاءلة أحرف المضارعة عليها ، فقد حذفت تاء المضارعة اكتفاءً بالتاء ، وما يدل على هلى على المتكلم والمتكلمين اكتفاءً بالهمزة والنون ، وتاء التأنيث في المفردة الغائبة اكتفاءً بلالة حرف المضارعة ، وكذلك عدم وجود صيغة خاصة بالمثنى المخاطب المؤنث. 
وليهذا الحذف والاكتفاء بُعد آخر ، يتعلق باستتار الضمير وجوبًا وجوازًا ، والذي يمكن أن نستنجه أنه إذا كانت دلالة حرف المضارعة على الثلى الثخص مطُّردة

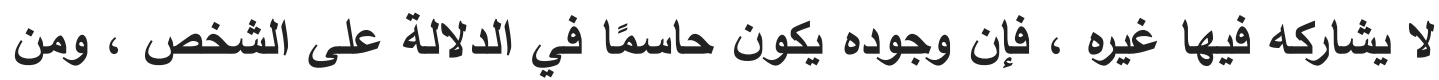

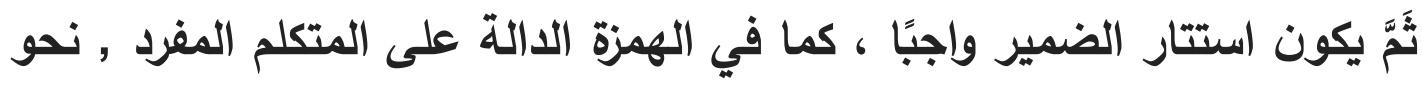

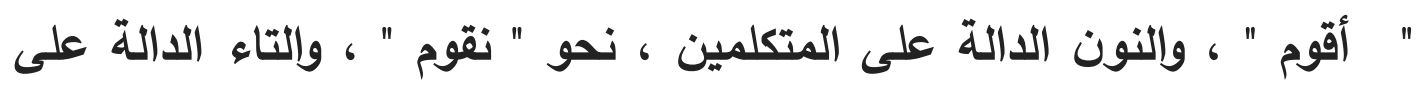

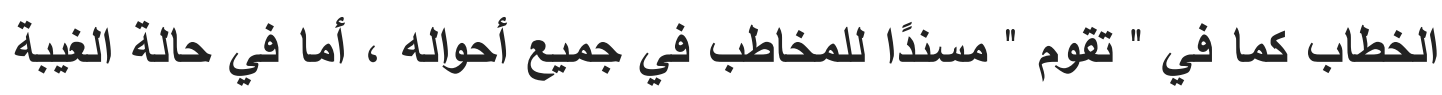

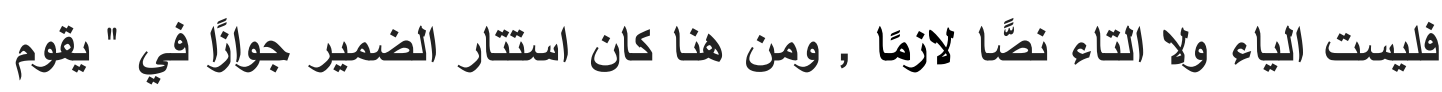

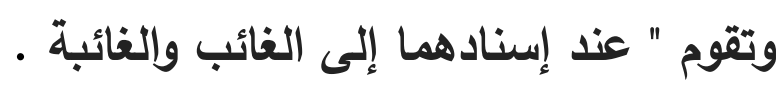

وباعتبار الضمائر لواحق للأفعال فإنها تؤدي دورًا مزدوجًا إذ تدل على النوع

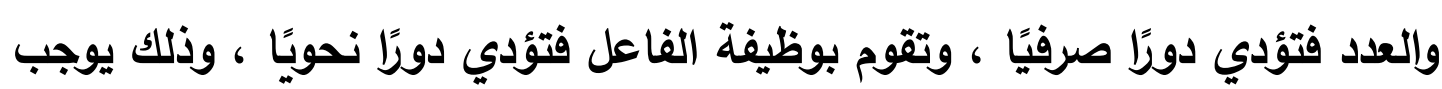

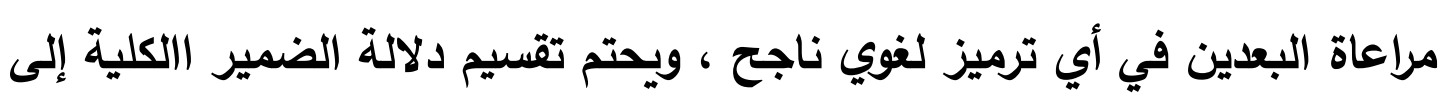

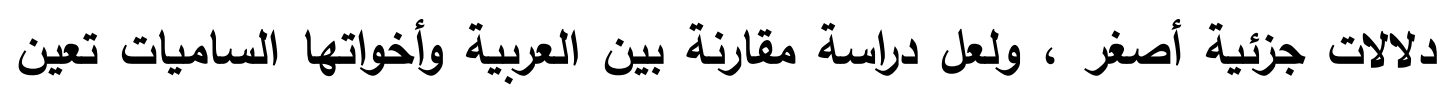

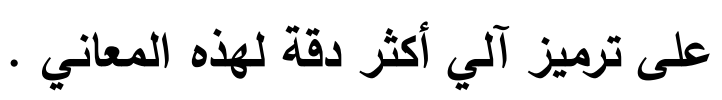

ولبعض اللواحق ارتباط معين بما تلحق به يمكن أن يكون علامة فارقة ؛

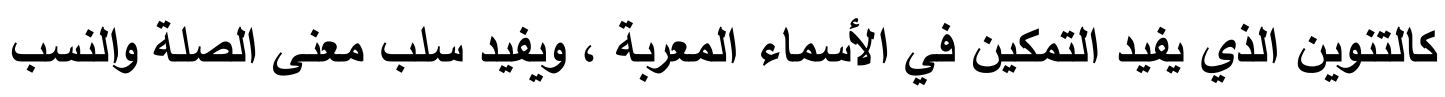

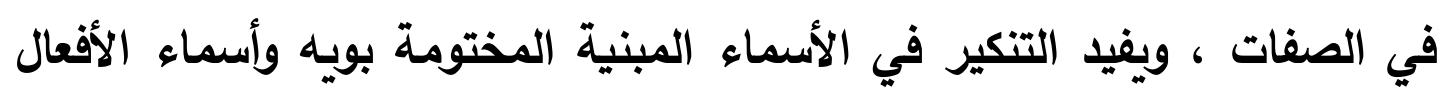

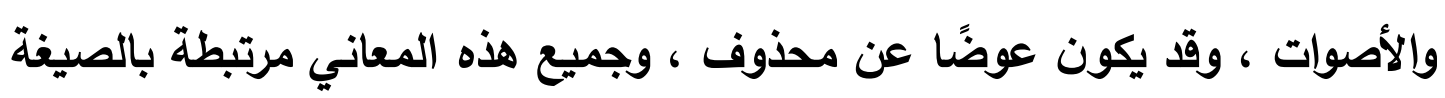

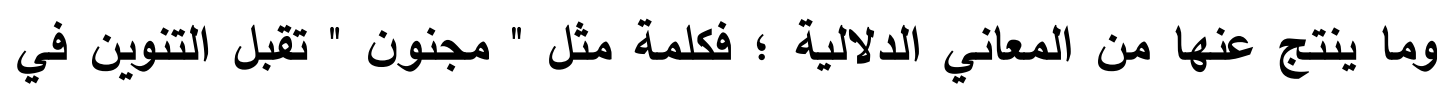

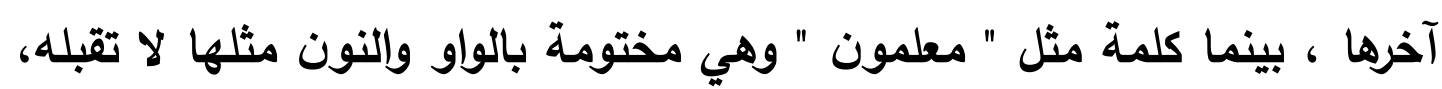

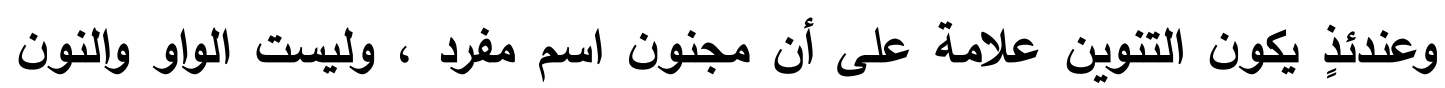

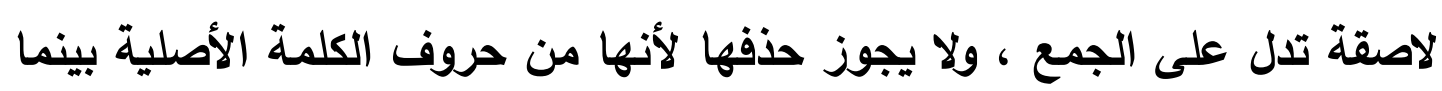

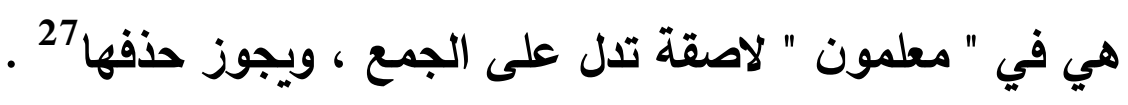
-727. أقسام الكلام العببي ، د. فاضل الساقي : 200 . 
ومثل التنوين في الرمزية " ال " ، فهي للتعريف بأنواعه مع الأسماء ، وليست كذلك مع الصفات ، وإنما هي اسم موصول ، ويرجع ذلك إلى طبيعة دلالة الصفة نفسها وليس إلى " ال " ، فالصفات تدل على موصوف بالحدث ، فتكون ذات صلة به من نوع معين ، وهذه الصلة توجد جهة شراكة بين الصفات والأفعال، لمال يجب مراعاتها عند الترميز للحوسبة الآلية 28 .

ومن اللواحق أيضا " ياء النسب " التي تلحق الأسماء فتدل على نسبتها إلى المجرد منها ، فيصير في معناه اسمًا للمنسوب ، ويعامل معاملة الصفة المشبهة في رفعه الظاهر والمضمر باطراد كقولك : زيد قرشيّ أبوه ، وهي لاحقة لا تقبل أن يكون معها غيرها ، ولذا فهي علامة من العلامات التي ترد كل شيء إلى أصله ، وتؤكد اسمية اللفظ الأي تلحق به 29 .

وأيًا كانت الوحدات الإلصاقية ؛ فإنها تصلح لأن تكون علامة فارقة ، يقوم عليها الترميز الحاسوبي ، فإذا لم تكن بمفردها كافية يضاف إليها من العلامات الأخرى ما يجعلها تقوم بلورها قيامًا تامًا ، وإذا لم يجد الحاسوبيون ضالتهم فيما

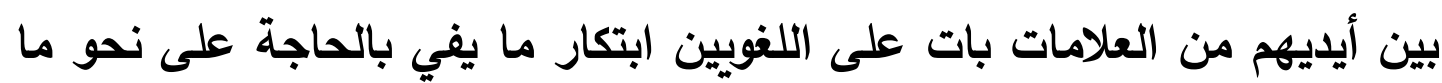
صنع تلاميذ أبي الأسود الدؤلي والخليل بن أحمد في أيام العربية الأولى .

\section{ثالثًا : علاقات الارتباط التركيبية :}

جاء في الأثباه والنظائر أن من علامات الاسم قيامه بمجموعة من الوظائف النحوية

مثل : الإسناد إليه ، وإضافته ، والإضافة إليه ، والإخبار به مع مباشرة الفعل ، ونعته ،

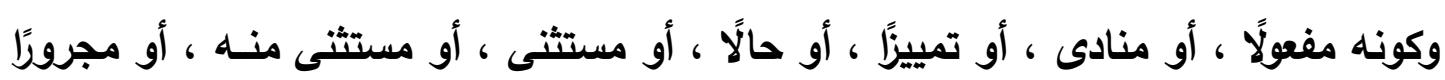

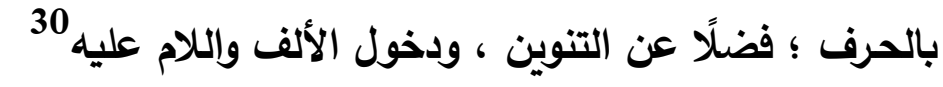

و28. اللغة العربية .. معناها ومبناها ، د. تمام حسان : 157 ـ 119

29. شذا العرف للحملاوي : 119 ـ الغة العربية .

30 
وقد يكون للفظ من خلال وجوده في تركيب معين علامات فارقة متعددة ؛ وعلى سبيل المثال يميز المبتدأ بأنه :

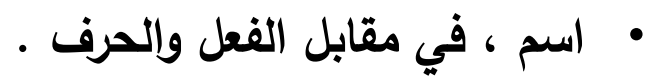

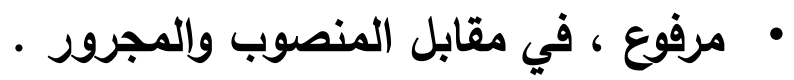

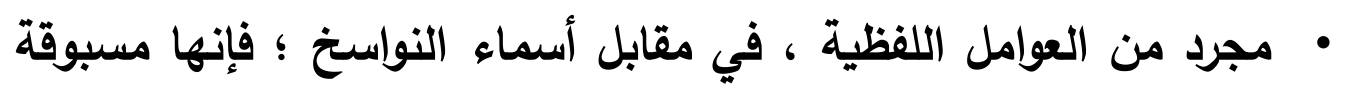
بالناستخ

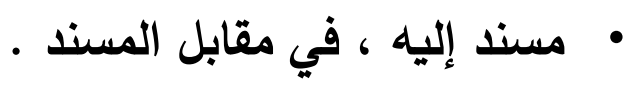
• مخبر عنه ، في مقابل الفاعل ونائبه .

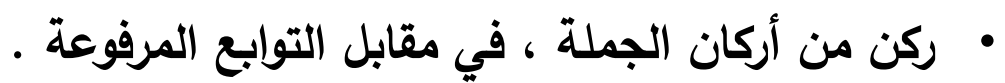

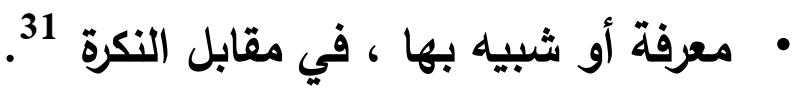

وقد جعل الاكتور تمام حسان هذه العلاقات قرائن معنوية تفيد في تحديد

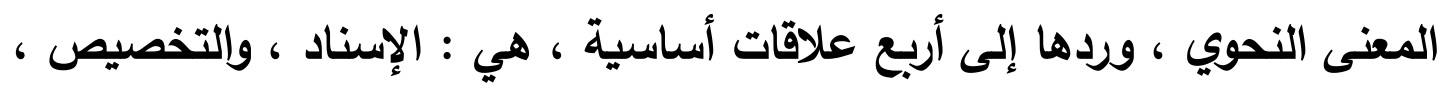

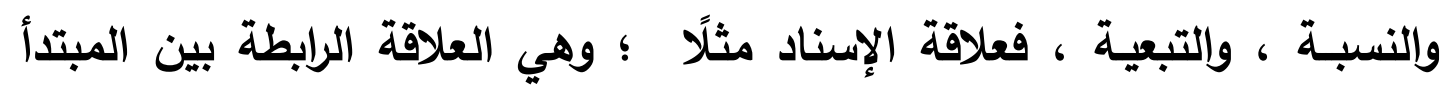

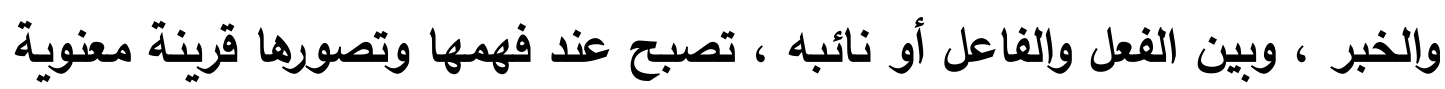
على أن الأول مبتدأ والثاني خبر , أو على أن الأول فعل والثاني فاعل أو نائب فاعل ، ولا نصل إلى هذا الحكم إلا عندما نفهم العلاقة الرابطة بين الجزأين فهما

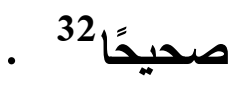

ومن المعلوم أن هذه العلاقات تتشابك وتتداخل في الجملة العربية ، حتى

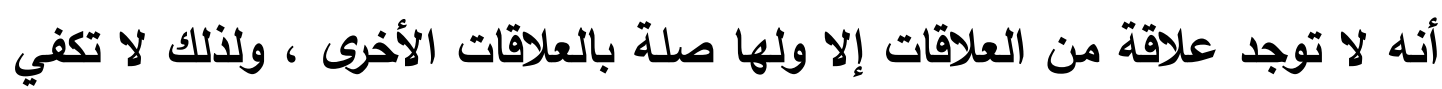

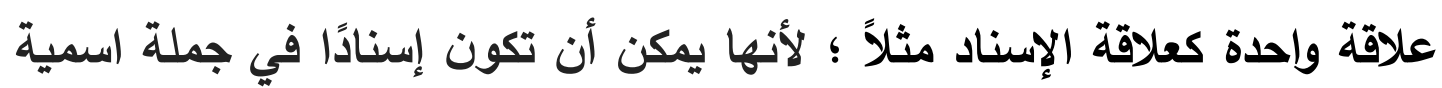

13. ينظر على سبيل المثال : شرح ابن عقيل على ألفية ابن مالك ، ومعل كتاب التوضيح والتكميل لثرح ابن

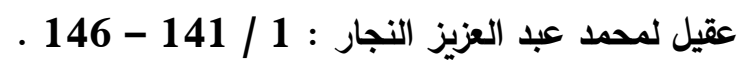
32 32 
أو فعلية , ويمكن أن تكون إسنادًا خبريًا أو إسنادًا إنثائيًا ، ومن هنا فإنها تحتاج

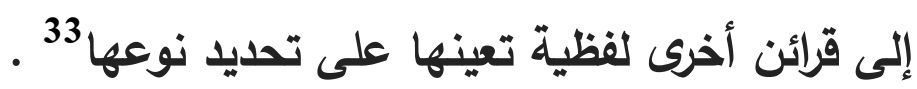

وعندئذٍ نلجأ إلى مباني التقسيم لنرى إن كان طرفا الإسناد اسمين ، أو

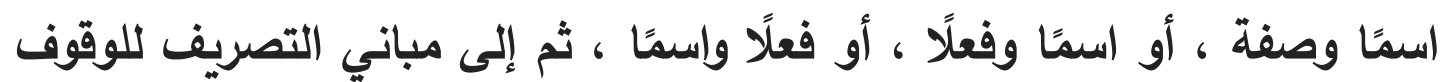
على قرائن الثخص والنوع والعدد والتعيين , وإلى العلامة الإعرابية لنرى ما إذا إلى التها كانت الأسماء مرفوعة أو منصوبة أو مجرورة , وإلى الرتبة لمعرفة النوع ، وإلى التى

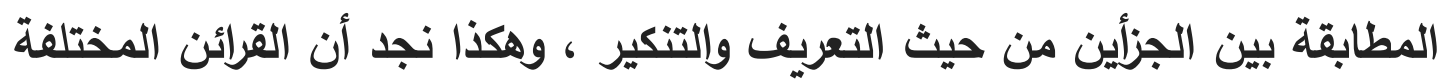
قد تضافرت لإيضاح المعنى الواحد .

ولتوضيح ظاهرة تضافر القرائن تطبيقيا بمثال يمكن أن نأخذ بشيء من التصرف تحليل الاكتور تمام حسان لجملة مشهورة عند النحويين ، هي : ضرب

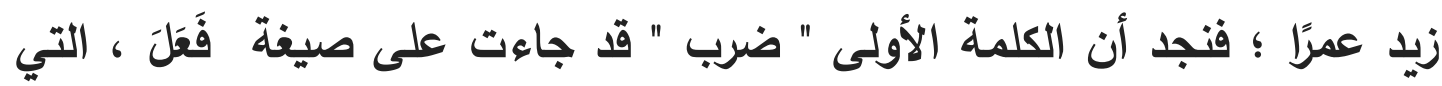

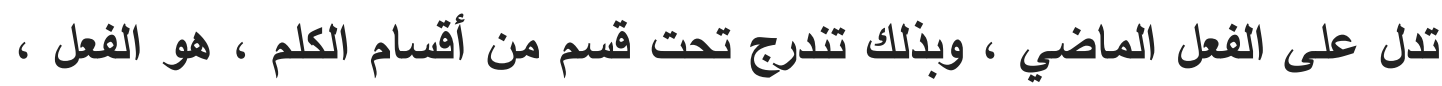
ومن هنا نحكم بأن ضرب فعل ماض , ثم ننظر بعد ذلك في " زيد " فنلاحظ ما لغا يأتي : ومن :

• أنه ينتمي إلى مبنى الاسم بقرينة الصيغة . • · وأن الفعل معه مبني للمعلوم بقرينة الصيغة أيضًا. • وأنه مرفوع بقرينة العلامة الإعرابية . · وأن العلاقة بينه وبين الفعل الماضي هي علاقة الإسناد بقرينة التعليق .

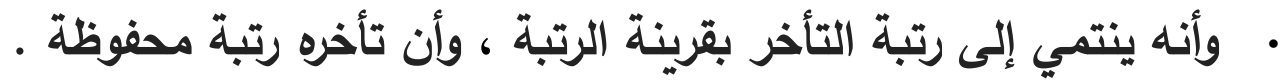
• وأن الفعل معه مسند إلى المفرد الغائب بقرينة المطابقة .

وبسبب كل هذه القرائن يُحم بأن " زيد " هو الفاعل للفعل السابق ، ثم ننظر في " عمرًا " فنجد : لهد

33. نظام الارتباط والربط في تركيب الجملة العببية ، د. مصطفى حميدة : 162. 


\section{• أنه ينتمي إلى مبنى الاسم بقرينة الصيغة . \\ • وأنه منصوب بقرينة العلامة الإعرابية .}

• وأن العلاقة بينه وبين الفعل هي علاقة التعدية بقرينة التعليق .

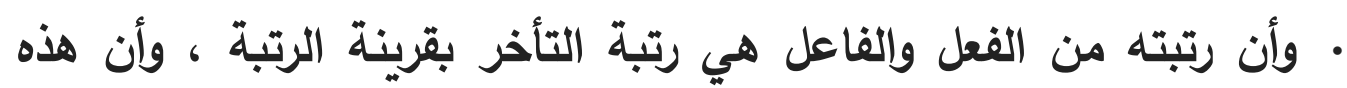

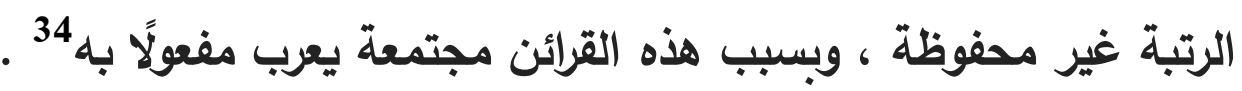

ولا شكَّ أن تضافر القرائن على هذا النحو يحتاج إلى تضافر الرموز والعلامات ؛ حتى تتم عمليات الحوسبة بنجاح ، وقد يصعب وضع الرمز المناسب

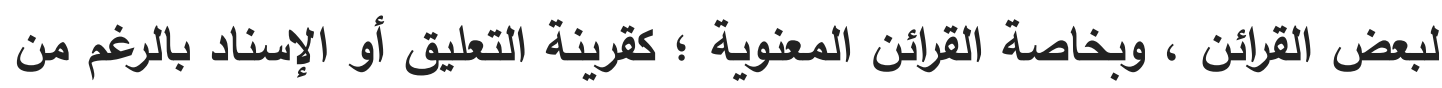
أنها أهم القرائن وأعظمها ، لكونها العلاقة التي تميز بين المسند والمسند إليه ،

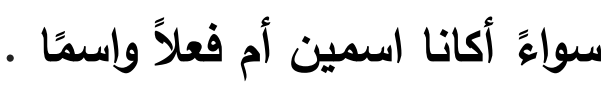

وقد تُشْكِل علينا بعض التراكيب في أثناء ترميزها ، وذلك بسبب الحذف ، أو التقديم والتأخير ، أو غير ذلك ؛ كما في أسلوب الاختصاص ، إذ إذ يجعلون الاسم

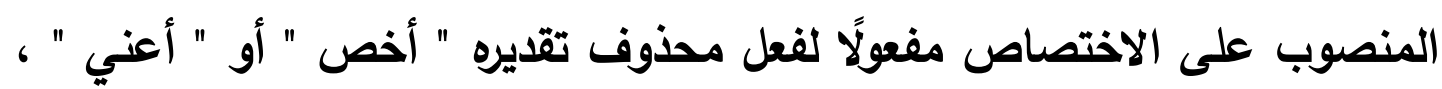
وكما في صيغتي التعجب ، وفي النداء ، وفي المنصوبات التي يتغير المعنى

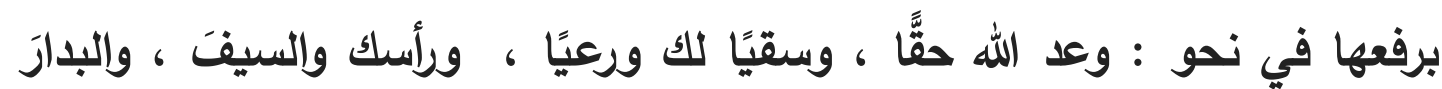
البدارَ ، ونحوه 35

وذلك كله يحتاج إلى عناية خاصة عند الترميز ، وقد يكون من الأنسب في

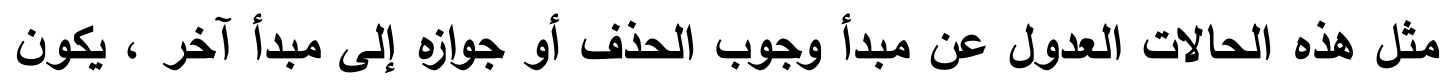
هو الأنسب لمعالجتها ، وهو الصيخ المسكوكة ، التي تقوم على قبول التراكيب

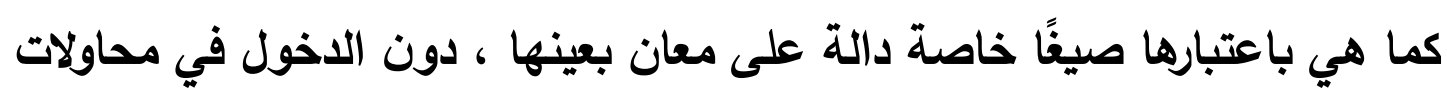

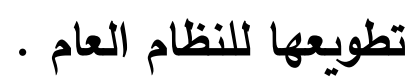

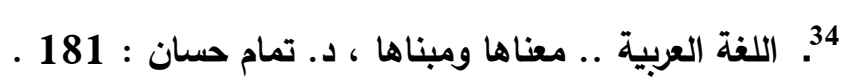

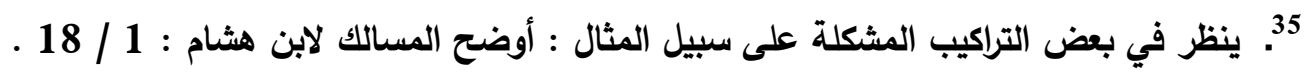




\section{رابعًا : حروف المعاني :}

من المشهور والمعروف أن من علامات الاسماء الجر بالإضافة أو

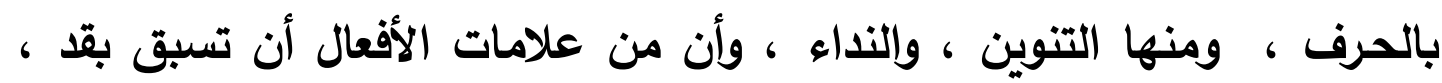

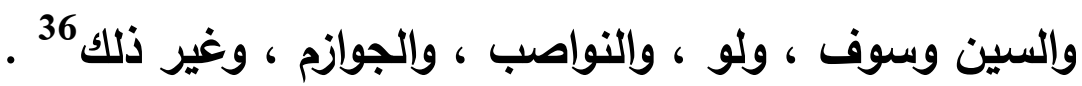

وتلك كلها قرائن يمكن أن نتظلب بها على تداخل الصيغ وتثابهها حال التركيب ، فنقوم بالربط بين مبنى الصيغة ومعانيها الصرفية ؛ كالجمع والتثنية

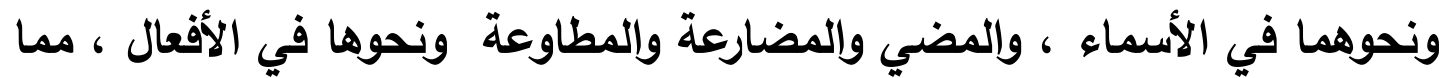
يعين على تحديد أدق لنوع الكلمة ، سواءً أكانت هذه المعاني بما تحمله الصيغة

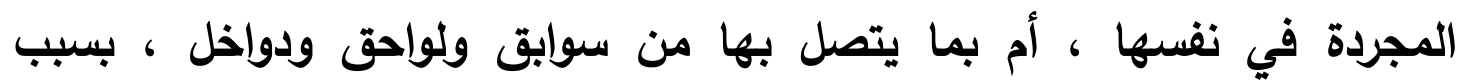

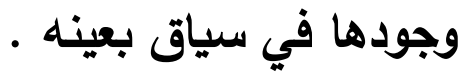

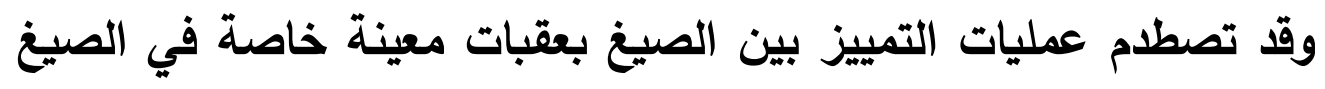

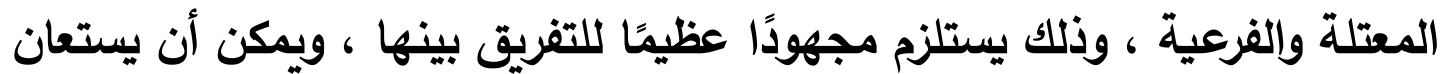

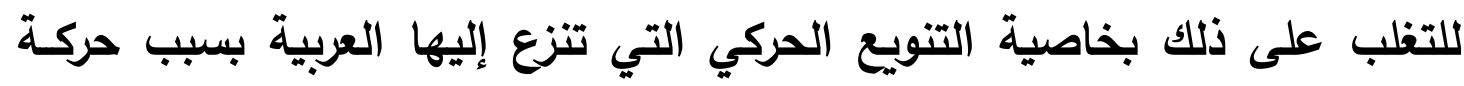

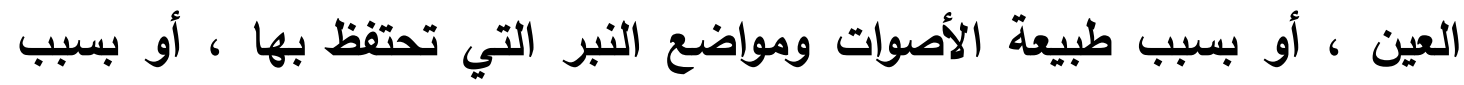

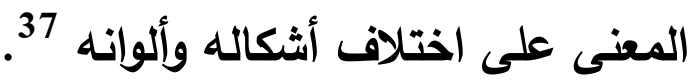

وفي خطوة تالية يمكن أن تدخل الجملة في التركيب فنحدد صلتها بما قبلها وما بعدها عن طريق شبكة علاقات الارتباط التركيبية ، ودلالات حروف المعاني

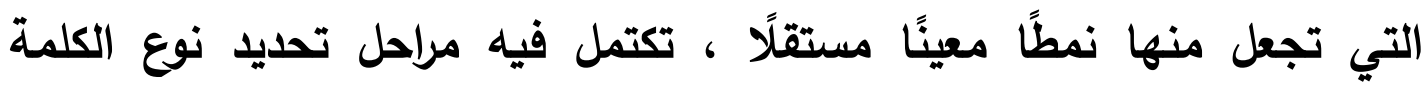
ووظيفتها داخل التركيب وخارجه .

6. ينظر في ذلك : ارتثاف الضرب لأبي حيان : 5 / / 2363 وما بعدها ، والأشباه النظائر في النحو

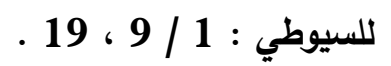
7. ينظر : التصريف العببي للطيب البكوش : 190 ، 191 . 
وتبقى بعض الكلمات ؛ كالحروف ، والضمائر ، والأسماء الأعجمية ،

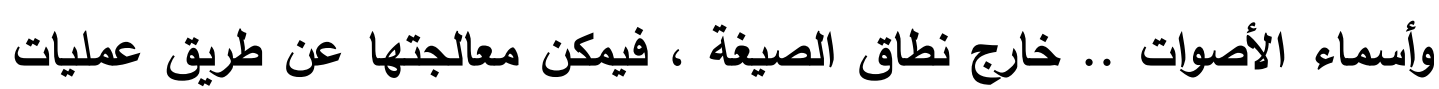

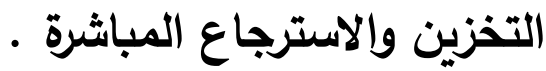

وفي جميع الحالات ؛ فإنه يمكن إجمال التصور الخاص بفكرة العلامات الفارقة بين أقسام الكلم مفردة ومركبة ، فنبأ بالصيغة الصرفية المفردة ، ونحاول

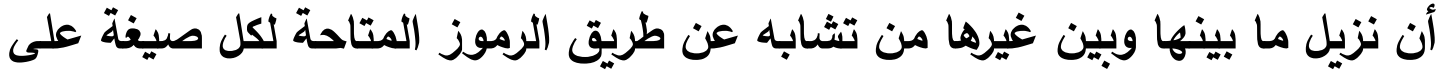

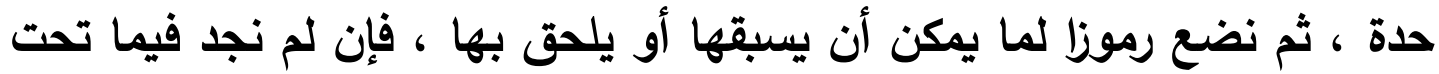
أيدينا مما هو عند السابقين نجتها في إيجاد الرموز البديلة ، كما اجتها أسلافنا من قبل يوم أن ضبطوا الحروف بنقط الإعراب ، وأزالوا إبهامها بنقط الإعجام ، فأحكما أمر اللفظ مفردًا ومركبًا .

وفي محاولة جادة ومبشرة لتطبيق ذلك عمليًا ؛ قام أحد الباحثين الثبان بإعداد قاعدة بيانات لحوسبة اللغة وإدراك النصوص آليًا ، فبدأ بإعداد ما أسماه بالخريطة الصرفية للأفعال ، حدد عليها الصيخ الأساسية للأفعال الصحيحة

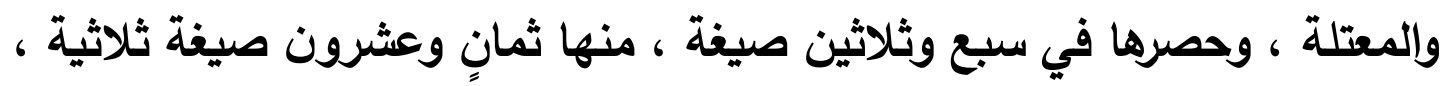

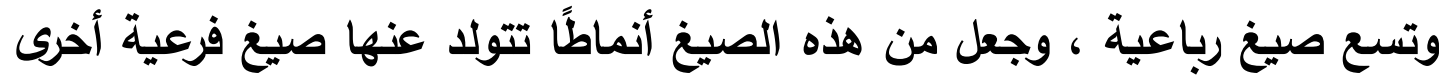

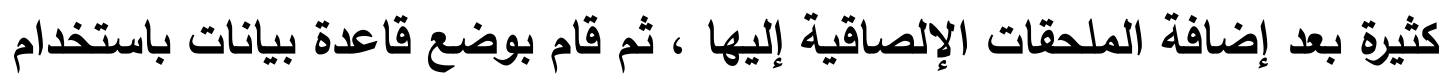

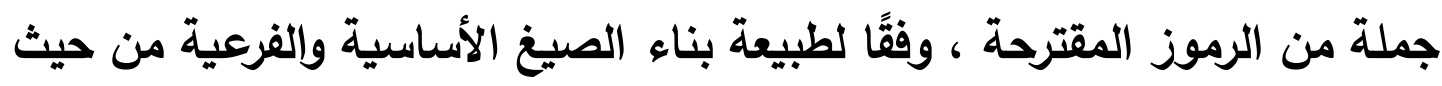

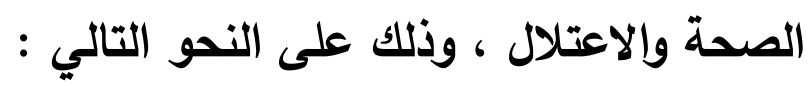

• الثرطة المائلة ( / ) رمز لأي حرف من حروف الهجاء العربية . • علامة العطف الأجنبية ( \& ) رمز للحرف السالم في الفعل الصحيح. • علامة الاستفهام ( ؟ ) ) رمز للحرف الصحيح في الفعل المعتل.

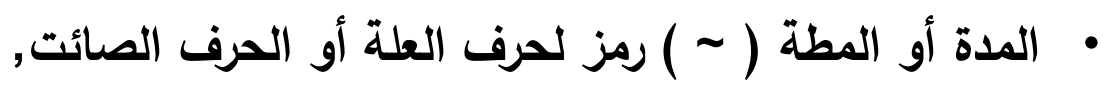
• • علامة الدولار ( \$ ) رمز للهمزة بأثكالها المختلفة. 
• العلامة الرياضية ( + ) رمز لعلامات الضبط الأصلية : الضمة ، ماكسة والفتحة ، والكسرة ، والسكون.

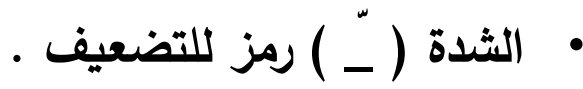

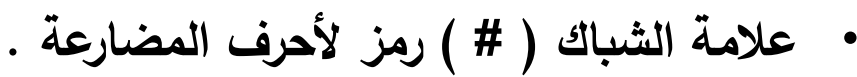
• علامة التعجب ( ! ) رمز للحروف الملصقة بالصيغة الأساسية. • النجمة ( * ) رمز لمجموعة غير معينة من الحروف أو الحركات. • علامة الزاوية ( ^ ) ) رمز للحركات الأصلية والتنوين. • أحرف الزيادة العثرة التي تجمعها عبارة " سألتمونيها " تأتي بثكلها في النمط بين الرموز السابقة وفقًا لترتيبها في الفعل .

وتبعًا لهذا المقترح رمز للأفعال على النحو التالي:

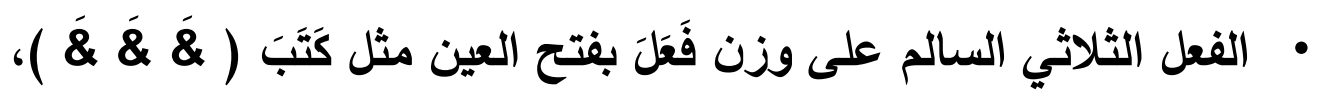

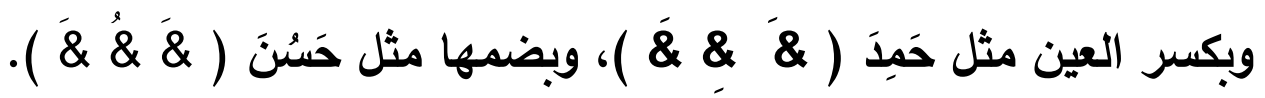

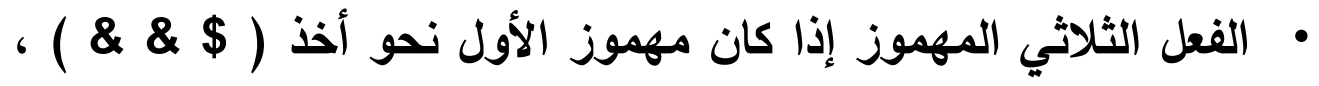

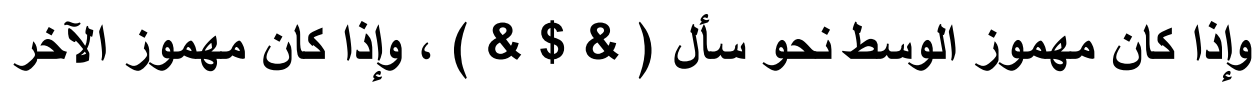

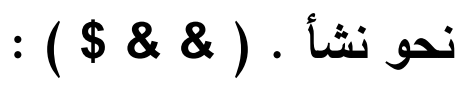
• الفعل الثلاثي المعتل إذا كان مثالًا نحو وَقَفَ ( ج ؟ ؟ ) ) ، وإذا كان

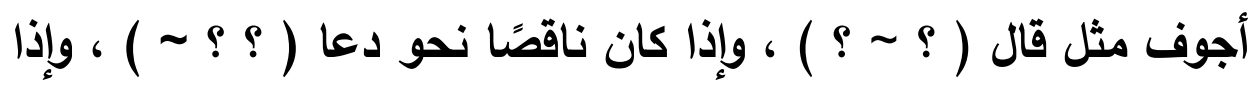
كان لفيفًا مفروقًا نحو وعى ( ؟ ) ) ، وإذا كان لفيفًا مقرونًا مثل

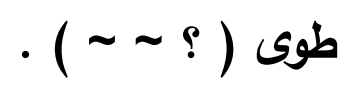

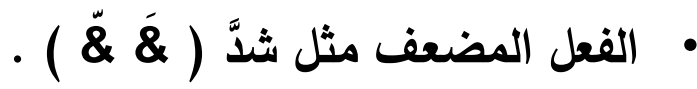

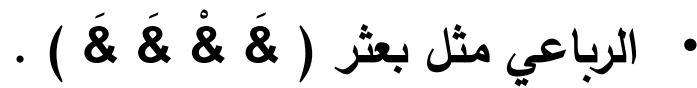

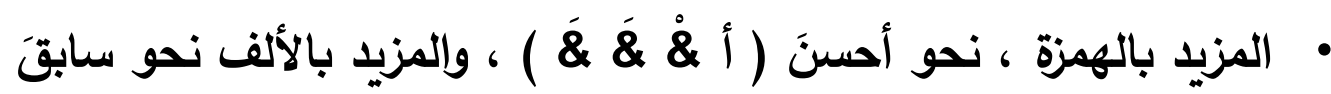

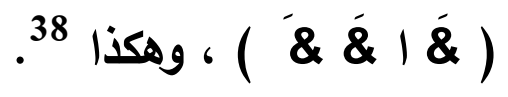

838. الخصائص الصرفية والنحوية للأفعال في العربية وطرق إدراكها بالحاسب الآلي ، محم رأفت محمود : 46 
وقد يؤخذ على هذه المحاولة - على ما فيها من جدية وابتكار - أنها اعتمدت على بعض الرموز الأجنبية التي لا تعرفها العربية ، ولو اقتفى أثر علماء

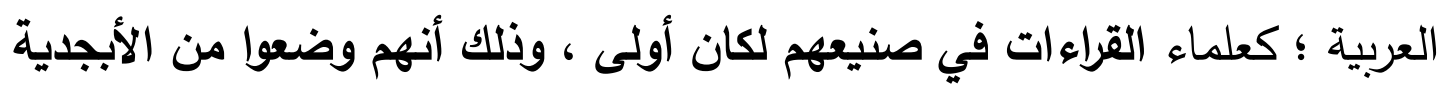
العزبية رموزًا للقراء ورواتهم منفردين أو مجتمعين ؛ فجعلوا الهمزة رمزًا للإمسام

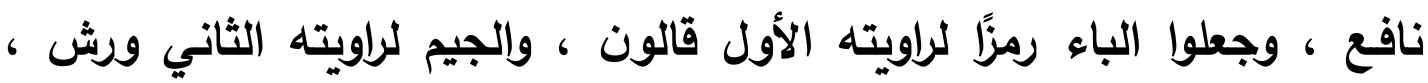
وجعلوا لابن كثير وراوييه الدال والهاء والزاي ، وهكذا صنعوا مع سائر القراء والرواة ، وجعلوا الخاء للدلالة على اجتماع القراء عدا نافعًا ، وجعلوا الثاء للدلالة

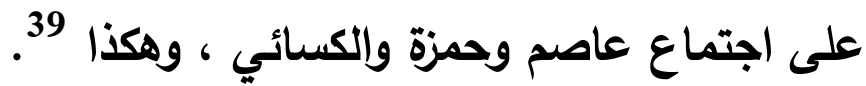

كما أن الرموز المستعملة تفتقر إلى حدية الخصوصية ، فالهمزة مثلاً دخلت تحت أكثر من علامة كالثرطة المائلة ، وعلامة الاستفهام ، وعلامة الدولار ، والحركات دخلت تحت علامة الجمع الرياضية وعلامة الزاوية ، والحرف الصحيح دخل تحت أكثر من علامة ، ولو استقل كل منها برمز واحد لكان أفضل ، ولكنها خطوة رائدة على الطريق .

والخلاصة ؛ أنه بجانب ما أثير إليه في نهاية كل مسألة من نتائج ؛ فإن النتيجة الكبرى التي نخرج بها أن الحاجة تبدو ملحة وماسة إلى حثد أكبر قدر

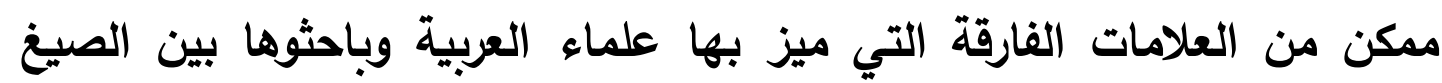
والألفاظ حال إفرادها أو تركيبها ؛ لتكون أمام الحاسوبيين والمبرمجين لاستعمالها لهاء عند وضع قواعد البيانات الخاصة بالإدراك الآلي للفة ، فإذا عدمنا ضالتنا فيما بين أيدينا من علامات فلنبحث عنها في مصادر أخرى ، فإن لم نجد فلنبتكر علامات جديدة كما صنع الأولون عند حاجتهم ؛ كأبي الأسود الدؤلي في نقط الإعراب ، ونصر بن عاصم ويحيى بن يعمر في نقط الإعجام ، والخليل بن أحمد في تحويره لنقط الإعراب ليكون من صور الحروف بلالاً من أن يكون نقطاً . 39. تنظر تلك الرموز وما تدل عليه وكيفية استعمالها في : الوافي في شرح الثاطبية ، للشيخ عبد الفتاح

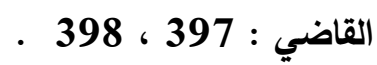


• • حسان ، د .تمام :

م اللغة العربية .. معناها ومبناها ، القاهرة ، الهيئة المصرية العامة

للكتاب ، 1973 م. 1973 م.

م اللغة بين المعيارية والوصفية ، القاهرة ، عام الكتب ، ط 4 : ،

$$
\text { - } 2001 \text { - 1421 }
$$

• الحملاوي ، الثيخ أحمد : شذا العرف في فن الصرف ، القاهرة ،

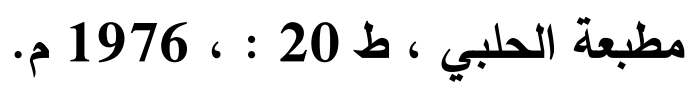

• حميدة ، د .مصطفى : نظام الارتباط والربط في تركيب الجملة العربية

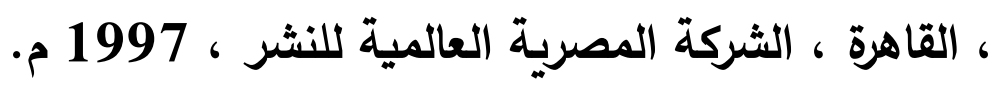

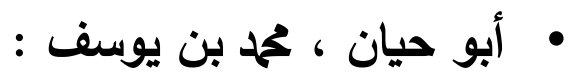

م ارتشاف الضرب ، تحقيق : د ـرجب عثمان ، القاهرة ، مكتبة

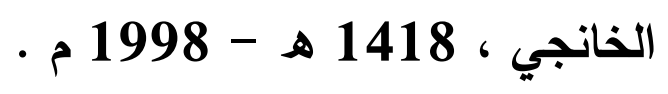

O البحر المحيط ، الرياض ، مطابع النصر الحديثة ، دـ .ت.

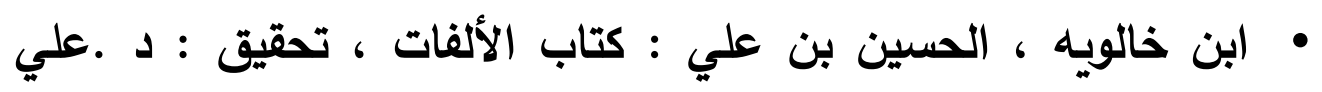

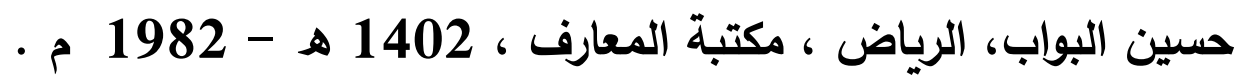

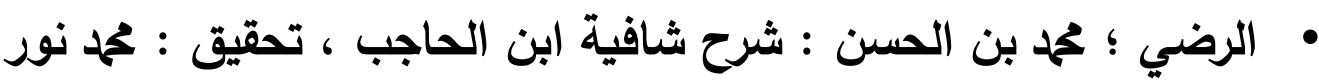
الحسن ورفيقيه ، بيروت ، دار الكتب العلمية ، 1395 هـ - 1975 م

• الزجاجي ، عبد الرحمن بن إسحاق : كتاب اللامات ، تحقيق : د .مازن

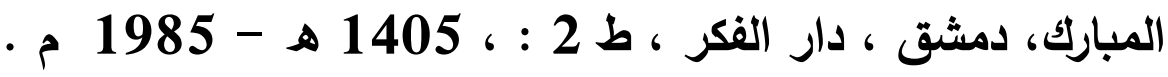

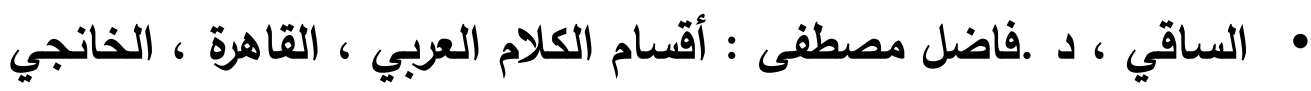

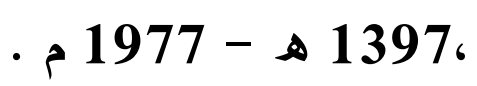

• السيرافي ، الحسن بن عبد الله : أخبار النحويين البصريين ، القاهرة ، مصطفى الحلبي ، 1374 هـ - 1995 م . 
• السيوطي ، جلال الدين عبد الرحمن : الأثثباه والنظائر في النحو ، تحقيق : طه عبد الرووف سعد ، القاهرة ، مكتبة الكليات الأزهرية ، . 1975

• الطيب البكوش : التصريف العربي من خلال علم الأصوات العديث ، تونس ، الثركة التونسية لفنون الرسم ، 1975 م .

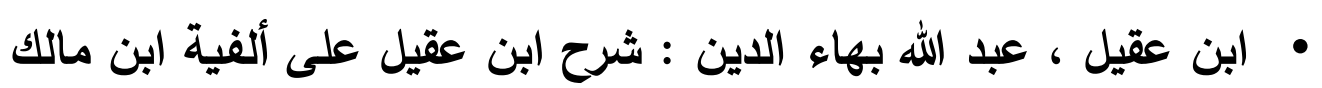

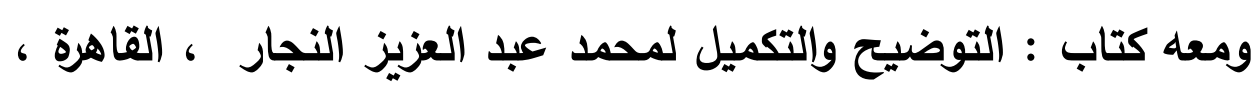
مطبعة الفجالة الجديدة ، 1386 هـ - 1366 هـ 1966 م .

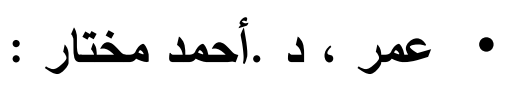
م دراسة الصوت اللغوي ، القاهرة ، عالم الكتب، 1976 م. م.

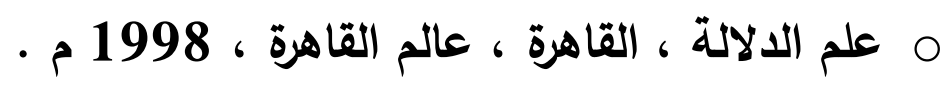

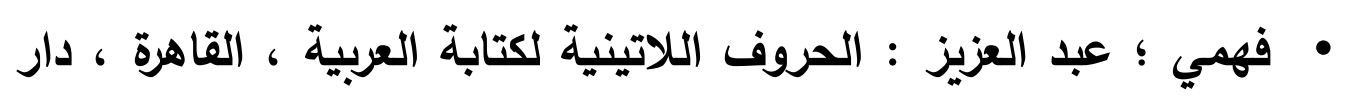

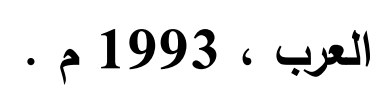

• القاضي ، الثيخ عبد الفتاح : الوافي في شرح الثاطبية في القراءات

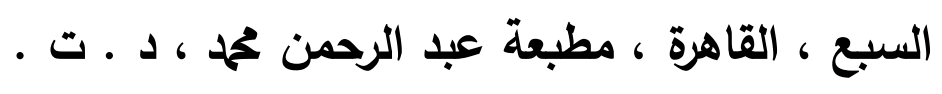

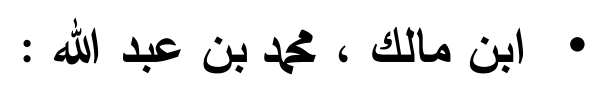
O ألفية ابن مالك ، مكة المكرمة ، مكتبة الفكر العربي ، 1390 ، 1390 هـ • 1970

0 التذييل التكميل • المرادي ، الحسن بن قاسم : الجنى الاني في حروف المعاني، تحقيق:

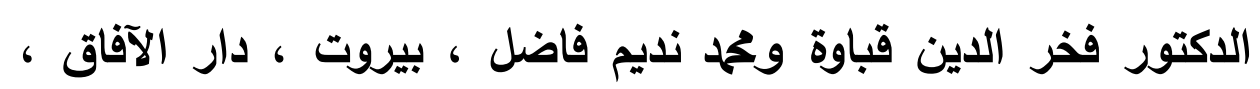

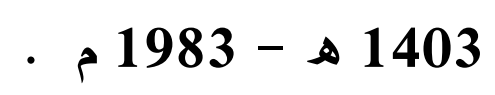
• مجمع اللغة العربية : مهن o المعجم الكبير ، حرف الهمزة ، القاهرة ، مطبعة دار الكتب ، - 1970 
o المعجم الوجيز ، القاهرة ، طبعة خاصة بوزارة التربية والتعليــــم ،

$$
\text { - } 1416 \text { هـ - } 1495
$$

• محمود ؛ د. محما رأفت : الخصائص الصرفية والنحوية للأفعال في ماكي العربية وطرق إدراكها بالحاسب الآلي ، رسالة دكتوراه بآداب بني

$$
\text { سويف - قسم اللغة العربية ، } 1435 \text { هـ - } 2014 \text { م • }
$$

• ابن منظور ، محمد بن مكرم : لسان العرب ، القاهرة ، الدار المصرية

$$
\text { للتأليف والترجمة والنشر ، د د .ت. }
$$

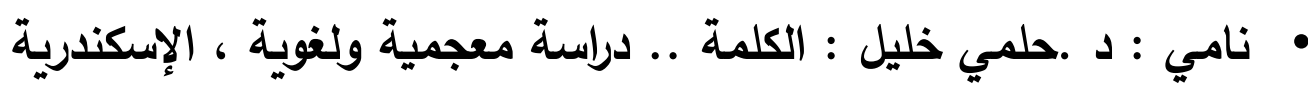

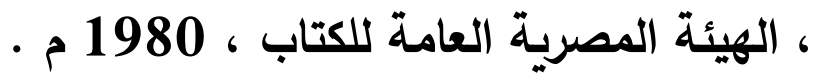

• ابن هثام ، جمال الدين بن يوسف : أوضح المسالك القاهرة ، مطبعة

$$
\text { صبيح ، } 1378 \text { هـ - } 1968 \text { م . }
$$

